\title{
The synthesis and application of nano doxorubicin- indocyanine green matrix metalloproteinase- responsive hydrogel in chemophototherapy for head and neck squamous cell carcinoma
}

\author{
This article was published in the following Dove Medical Press journal: \\ International Journal of Nanomedicine
}

\author{
Huan-huan Wang ${ }^{1, *}$ \\ Zhi-guang $\mathrm{Fu}^{\mathrm{l}, *}$ \\ Wei $\mathrm{Li}^{2}$ \\ Yun-xia Li' \\ Li-sheng Zhao' \\ Li Wen' \\ Jian-jun Zhang ${ }^{2}$ \\ Ning Wen' \\ 'Department of Stomatology, Chinese \\ PLA General Hospital, Beijing \\ I 00853, China; ${ }^{2}$ College of Chemical \\ Engineering, Beijing University \\ of Chemical Technology, Beijing \\ 100029, China \\ *These authors contributed equally \\ to this work
}

\begin{abstract}
Background: Head and neck squamous cell carcinoma (HNSCC) is one of the most common malignancies, with high rates of mortality and morbidity worldwide. Owing to the special anatomical location of this tumor, an effective, minimally invasive treatment with low systemic toxicity is highly desirable. Hydrogels have shown great potential for tumor-targeting therapy, with excellent performance. However, there have been few reports on co-loading photosensitizers and chemotherapeutic drugs into hydrogels. In this study, we synthesized a nano doxorubicinindocyanine green matrix metalloproteinase (MMP)-responsive hydrogel (denoted as NDIMH), combining chemotherapy and phototherapy, to achieve superior antitumor efficacy.
\end{abstract}

Methods: First, NDIMH was synthesized and characterized by scanning electron microscopy and drug-release assays. Second, the photosensitivity properties and antitumor efficiency of this drug delivery system were studied in vivo and in vitro. Last, the imaging and biodistribution of NDIMH were monitored using the Maestro EX in vivo imaging system.

Results: The nanodrugs loaded into the smart hydrogel exhibited uniform size distribution, excellent size stability, and a sustained release in the presence of MMP-2. NDIMH showed ideal photosensitivity characteristics under light. NDIMH with $808 \mathrm{~nm}$ near-infrared (NIR) irradiation effectively inhibited the viability, invasion, and metastasis of SCC- 15 in vitro. After intratumoral injection of NDIMH with $808 \mathrm{~nm}$ NIR illumination, the hydrogels exhibited favorable synergistic antitumor efficacy and acceptable biosafety. Additionally, fluorescence imaging showed that NDIMH could significantly improve the retention of nanodrugs at the tumor site. Conclusion: The intratumoral injection of NDIMH with $808 \mathrm{~nm}$ NIR irradiation could be a promising chemophototherapy alternative for HNSCC.

Keywords: hydrogel, MMP-responsive, doxorubicin, indocyanine green, chemophototherapy

\section{Introduction}

Head and neck squamous cell carcinoma (HNSCC) is the sixth most common cancer worldwide, and has high rates of mortality and morbidity. ${ }^{1,2}$ Present treatment options include surgery, radiotherapy, conventional chemotherapy, and combination therapies. Owing to the specific location of anatomical structures (breathing and swallowing), surgical excision of tumor tissues in these regions could cause unnecessary damage to adjacent or underlying tissues. Furthermore, most of these tumors occur on superficial areas, and patients are frequently concerned about scarring after surgery. ${ }^{3}$ Radiation therapy may have long-term side effects on normal cells, leading to xerostomia, osteoradionecrosis, and so on. ${ }^{4}$ At present, chemotherapy often requires multiple doses to be 
effective, which results in increasingly severe systemic toxicity and drug resistance over the treatment course. ${ }^{5}$ Despite recent progress in screening, diagnosis, and management owing to new technologies and increased awareness, the overall survival rates of HNSCC have remained relatively stagnant over the past decades. ${ }^{6}$ Local and regional disease, whether from primary or secondary tumors, is the major factor contributing to the poor survival rates. ${ }^{7}$ Therefore, effective, minimally invasive treatments directed specifically to local disease sites with less systemic toxicity are highly desirable.

Injectable hydrogel-based drug delivery systems for local cancer therapy have attracted tremendous attention owing to their excellent performance and favorable characteristics such as easy formulation, targeted injection, biodegradability, and sustained drug release..$^{8-10}$ Chemotherapeutic drugs, biological agents, and other drugs are commonly intratumorally injected with hydrogels. Localized therapy with injectable hydrogels not only increases the concentration of chemotherapeutics at the target tumor site, thereby enhancing the efficacy of the treatment, but also avoids damage to normal tissues and diminishes systemic toxicity. ${ }^{8}$ To improve drug targeting delivery and bioavailability, smart hydrogels responding to different stimuli have been developed with spatial, temporal, and dosage control., ${ }^{9} 10$ Matrix metalloproteinases (MMPs), a family of extracellular enzymes involved in cancer initiation, progression, and metastasis, can degrade the natural extracellular matrix (ECM) and basement membrane, opening up more space for tumor growth. ${ }^{11,12}$ Recently, smart MMP-responsive drug delivery systems have shown great potential in cancer diagnosis and therapy owing to the frequent overexpression of these enzymes in solid tumors. ${ }^{13}$ However, results regarding injectable hydrogels for localized co-delivery of anticancer drugs for combination cancer therapy are still limited.

Light-based therapies, including photodynamic therapy (PDT) and photothermal therapy (PTT), have been applied clinically for curative and palliative treatment of HNSCC because of their minimal invasiveness, good targeting, slight adverse reactions, and potential for repeated treatment. ${ }^{14-16}$ Compared with ultraviolet/visible light, near-infrared (NIR) irradiation can achieve maximum penetration depth and minimum autofluorescence in biological species ${ }^{17}$ However, monotherapies may result in incomplete tumor killing and recurrence is often seen. ${ }^{5}$ The combination of chemotherapy and phototherapy has emerged as a promising strategy for cancer therapy, preclinically and clinically. 5,18 Concurrent introduction of chemotherapeutics can enhance the efficacy of phototherapy by further damaging tumor cells, preventing regrowth. Additionally, anticancer drugs themselves may generate oxidative stress, producing hydroxyl radicals which, when combined with PDT, may be sufficient to induce cell cycle arrest and subsequent cytotoxic death of cancer cells. ${ }^{19}$

PDT is usually combined with PTT in nanoparticles. Both techniques require light absorption, whereas photosensitizers generate ROS under light, and photothermal conversion agents convert optical energy into heat to induce cancer cell death. ${ }^{20}$ Indocyanine green (ICG) is a US Food and Drug Administration (FDA)-approved dual-functional agent and has been applied in optically mediated diagnosis and phototherapy. ICG, as a photosensitizer, can absorb NIR light, convert it into cytotoxic heat (PTT), and produce ROS, which can induce mitotic cell death in dividing cells (PDT) in tumor treatment. ${ }^{21,22}$ ICG has the unique side effect of sunlight toxicity. Doxorubicin (DOX) is a broad-spectrum antineoplastic drug that shows excellent therapeutic efficacy. However, its use is limited by drug resistance and its side effects, which include cardiotoxicity, myelosuppression, alopecia, nausea, and vomiting. ${ }^{23,24}$ Nanosizing antitumor drugs can effectively improve their water solubility and stability, enhance drug utilization and antitumor activity, reduce normal tissue toxicity, and solve the problem of multidrug resistance. ${ }^{25}$ Increasingly, studies are focusing on loading different chemotherapeutic drugs into hydrogels for better antitumor efficacy. However, there have been few reports on co-loading photosensitizers and chemotherapeutic drugs into hydrogels. ${ }^{8,26-28}$

In this study, we synthesized nano DOX-ICG MMPresponsive hydrogel (denoted as NDIMH) for the treatment of SCC-15. It showed a sustained release of DOX and ICG nanoparticles (abbreviated as nano DOX and nano ICG) and could be effectively degraded in the tumor microenvironment. The photosensitivity properties of NDIMH were evaluated, and the effects of NDIMH with $808 \mathrm{~nm}$ NIR irradiation, combining the therapeutic modalities of chemotherapy and phototherapy, in SCC- 15 were investigated. The in vivo synergistic antitumor efficiency and biosafety of the hydrogel treatment were studied by intratumoral injection of NDIMH with $808 \mathrm{~nm}$ NIR irradiation in nude mice bearing human SCC-15 xenografts. Furthermore, the fluorescence (FL) of NDIMH was monitored to determine its localization and metabolic distribution.

\section{Materials}

DOX hydrochloride (DOX $\cdot \mathrm{HCl})$ was purchased from Beijing Zhongshuo Pharmaceutical Technology Development Co. 
Ltd. (Beijing, China). ICG, MTT, and H\&E were obtained from Sigma-Aldrich (St Louis, MO, USA). MMP-2 was purchased from Sino Biological (Beijing, China). DMEM, FBS, trypsin EDTA, penicillin, and streptomycin were acquired from Hyclone (Logan, UT, USA). Reactive Oxygen Species Assay Kit and ROS Assay Kit were purchased from Beyotime (Shanghai, China). Other reagents were obtained from the Chemical Reagent Company (Beijing, China). SCC15 cells were purchased from the American Type Culture Collection (Manassas, VA, USA). The transwell system was purchased from Millipore (Billerica, MA, USA). HSMMP-SH (GCREG-PQGIWGQ-ERCG) was obtained from GenScript (Piscataway, NJ, USA).

\section{Methods}

\section{Synthesis and characterization of nano DOX/ICG MMP-responsive hyaluronic}

\section{acid hydrogel}

Preparation and characterization of nano DOX and nano ICG

Nano DOX and nano ICG were prepared using solventantisolvent method. First, $20 \mathrm{mg}$ of free DOX $\cdot \mathrm{HCl}$ and $16 \mu \mathrm{L}$ triethylamine (TEA) were dissolved in $4 \mathrm{~mL}$ of dimethyl sulfoxide and then $40 \mathrm{~mL}$ of PBS (150 mM, pH 7.4) was added into the polymer solution with vigorous stirring. The nanoparticles were purified by dialysis against PBS (15 mM, $\mathrm{pH}$ 7.4) to remove the organic solvent. Finally, the solution was lyophilized to form nano DOX. The nano ICG was synthesized with the similar steps, except that it did not need TEA to neutralize. The size, surface potential, and size distribution of the nanodrugs were measured by dynamic light scattering (DLS; Malvern Zeta Sizer Nano Instrument ZS90, Malvern, UK) at room temperature. The morphological and particle size examination of nanodrugs were obtained by transmission electron microscopy (TEM; TECNAI 20).

\section{Synthesis of HA-Ac}

Following the protocol of Lei et $\mathrm{al},{ }^{29}$ we synthesized hyaluronic acid-acrylate (HA-Ac) via a two-step method. Briefly, HAadipic dihydrazide $(\mathrm{ADH})$ with amino group was prepared by a condensation reaction of acrylated HA (1.0 g, $60 \mathrm{Da})$ and $\mathrm{ADH}(18.0 \mathrm{~g})$ at $\mathrm{pH} 4.75$ with 1-ethyl-3-[3-dimethylaminopropyl] carbodiimide hydrochloride $(2.0 \mathrm{~g})$ overnight and purified through dialysis. Then, HA-ADH $(1.0 \mathrm{~g})$ was reacted with $N$-acryloxysuccinimide $(0.75 \mathrm{~g})$ in 4-(2-hydroxyethyl)1-piperazineethanesulfonic acid buffer ( $\mathrm{pH} 7.2)$ overnight and purified through dialysis to form HA-Ac.

\section{Loading of nano DOX and nano ICG into HA-Ac}

Nano DOX and nano ICG were accurately weighed and mixed with $40 \mu \mathrm{L}$ triethanolamine (TEOA) buffer, and then $8 \mathrm{mg}$ HA-Ac was mixed thoroughly with $160 \mu \mathrm{L}$ TEOA buffer. The above two solutions were mixed, and $2 \mathrm{mg}$ HS-MMP-SH cross-linking agent was added to them. The mixed solution was then placed in a $37^{\circ} \mathrm{C}$ thermostat for 5-8 minutes to gelate. The morphology and distribution of nanodrugs of NDIMH ( $4 \mathrm{mg} / \mathrm{mL}$ nano DOX and $6 \mathrm{mg} / \mathrm{mL}$ nano ICG) were observed by scanning electron microscopy (SEM; JSM-701). We used the same method to produce the MMP-responsive hydrogel (MH, 4\% HA-Ac), nano DOX MMP-responsive hydrogel (NDMH, $4 \mathrm{mg} / \mathrm{mL}$ nano DOX), and nano ICG MMP-responsive hydrogel (NIMH, $6 \mathrm{mg} / \mathrm{mL}$ nano ICG) for the sequential experiments.

\section{Tumor cells}

SCC-15 cells were utilized for cell studies. Cells were cultured in DMEM containing 10\% FBS, 1\% penicillin, and $1 \%$ streptomycin at $37^{\circ} \mathrm{C}$ in a $5 \% \mathrm{CO}_{2}$ atmosphere.

\section{Cytotoxicity of $\mathrm{MH}$}

The cytotoxicity of $\mathrm{MH}$ (4\% HA-Ac) was assessed using an MTT assay with a control group. SCC-15 cells were planted into 96-well plates (5,000 per well) and cultured in $100 \mu \mathrm{L}$ complete DMEM overnight $\left(37^{\circ} \mathrm{C}, 5 \% \mathrm{CO}_{2}\right)$. Then, the culture media was removed and the $\mathrm{MH}$ precursor solutions were added into the wells, followed by addition of $100 \mu \mathrm{L}$ fresh culture medium. After further incubation, the cytotoxicity was evaluated at 24,48 , and 72 hours.

\section{In vivo/ex vivo gel degradation}

MHs (4\% HA-Ac) were incubated in PBS in the presence and absence of MMP-2 $\left(1.0 \mu \mathrm{g} / \mathrm{mL}\right.$ at $\left.37^{\circ} \mathrm{C}\right)$. PBS containing MMP-2 was used as the degradation media, while PBS only was used as a control. The whole solution was replaced every day. At specific time points $(0,2,4,8$, and 16 days), the remaining gel was accurately weighed.

$\mathrm{BALB} / \mathrm{c}$ rats with tumors (18-20 g) were used for the in vivo test, and the rats without tumors were used as a control. In brief, $0.2 \mathrm{~mL}$ of $\mathrm{MH}$ aqueous solution $(4 \%$ HA-Ac) was subcutaneously injected into the dorsal area of the right anterior limb beside the tumor. At given time points $(0,7,14$, and 21 days), rats were sacrificed for photographic imaging of in situ hydrogel formation, and the dissected gels were weighed. 


\section{In vitro NDIMH release assay}

NDIMH (4 mg/mL nano DOX and $6 \mathrm{mg} / \mathrm{mL}$ nano ICG) was immersed into $1 \mathrm{~mL}$ of PBS with or without MMP-2 $(1.0 \mu \mathrm{g} / \mathrm{mL})$ and transferred into a dialysis bag, which was placed in a tube containing $20 \mathrm{~mL}$ of the same medium in a $37^{\circ} \mathrm{C}$ water bath. At predetermined time intervals, $1 \mathrm{~mL}$ of release medium was withdrawn from the tube and replaced by $1 \mathrm{~mL}$ of fresh medium. Release of nano DOX/nano ICG was measured by determining the absorption of the samples at 485 and 795 nm (Epoch ${ }^{\text {TM }}$ Multi-Volume Spectrophotometer System; BioTek, Winooski, VT, USA), respectively.

\section{Temperature measurements during laser irradiation}

Five hundred-microliter samples of free ICG, free nano ICG, NIMH, and NDIMH were transferred into wells of a 24-well plate. Nude mice bearing SCC-15 tumors were intratumorally injected with $100 \mu \mathrm{L}$ of free ICG, free nano ICG, NIMH, and NDIMH. The concentration of ICG in each group was $6 \mathrm{mg} / \mathrm{mL}$, and PBS was used as a control both in vivo and in vitro. The wells and tumors were irradiated using an NIR laser for 10 and 6 minutes, respectively $\left(808 \mathrm{~nm}, 1.0 \mathrm{~W} / \mathrm{cm}^{2}\right)$. Infrared thermographic maps were obtained using an infrared imaging camera (TiS20; Fluke, Everett, WA, USA).

\section{Intracellular ROS test}

Intracellular ROS generation was determined using a Reactive Oxygen Species Assay Kit (Beyotime), and 2', 7'-dichlorodihydrofluorescein diacetate (DCFH-DA) was employed as a chemical probe for detection. SCC- 15 cells $(5,000 /$ well $)$ were planted in Lab-Tek chambered cover glass systems (eight wells) in $200 \mu \mathrm{L}$ of medium and treated with the different samples - MH (50 $\mu \mathrm{L}, 4 \%$ HA-Ac), NIMH (50 $\mu \mathrm{L}$, $6 \mathrm{mg} / \mathrm{mL}$ nano ICG), NIMH (50 $\mu \mathrm{L}, 6 \mathrm{mg} / \mathrm{mL}$ nano ICG)+ NIR laser ( $808 \mathrm{~nm}, 0.5 \mathrm{~W} / \mathrm{cm}^{2}, 8$ minutes), and NDIMH $(50 \mu \mathrm{L}, 6 \mathrm{mg} / \mathrm{mL}$ nano ICG and $4 \mathrm{mg} / \mathrm{mL}$ nano DOX)+ NIR laser ( $808 \mathrm{~nm}, 0.5 \mathrm{~W} / \mathrm{cm}^{2}, 8$ minutes) - after 24 hours of culture. After 4 hours of treatment, DCFH-DA was added to stain the ROS. FL microscopy was used to detect the generation of intracellular $\operatorname{ROS}(\lambda$ ex $=488 \mathrm{~nm}, \lambda$ em $=525 \mathrm{~nm})$.

\section{In vitro cellular uptake of the nanoparticles} SCC-15 cells were seeded in Lab-Tek chambered cover glass systems (eight wells) at a density of 5,000 cells/well in $200 \mu \mathrm{L}$ of complete DMEM and incubated at $37^{\circ} \mathrm{C}$ in a $5 \% \mathrm{CO}_{2}$ atmosphere overnight. Then, the cells were cultured with $50 \mu \mathrm{L}$ of PBS, free DOX $(4 \mathrm{mg} / \mathrm{mL})$, free nano DOX $(4 \mathrm{mg} / \mathrm{mL})$, and NDIMH $(4 \mathrm{mg} / \mathrm{mL}$ nano DOX and $6 \mathrm{mg} / \mathrm{mL}$ nano ICG)+ NIR laser ( $808 \mathrm{~nm}, 0.5 \mathrm{~W} / \mathrm{cm}^{2}, 8$ minutes) for 4 hours at $37^{\circ} \mathrm{C}$. After incubation, the cells were washed three times with PBS, and the cellular uptake per group was visualized via confocal laser scanning microscopy (CLSM; TCS-SP5; Leica, Wetzlar, Germany).

\section{Cellular cytotoxicity analysis of NDIMH}

Cells were seeded onto 96-well plates at a density of $2 \times 10^{3 /}$ well and cultured in $100 \mu \mathrm{L}$ of DMEM overnight at $37^{\circ} \mathrm{C}$ in $5 \% \mathrm{CO}_{2}$. Then, the culture medium was removed and $20 \mu \mathrm{L}$ of the hydrogel precursor solutions, including $\mathrm{MH}$ (control, 4\% HA-Ac), NDMH (4 mg/mL nano DOX), NIMH (6 mg/mL nano ICG), NDIMH ( $4 \mathrm{mg} / \mathrm{mL}$ nano DOX and $6 \mathrm{mg} / \mathrm{mL}$ nano ICG), and NDIMH ( $4 \mathrm{mg} / \mathrm{mL}$ nano DOX and $6 \mathrm{mg} / \mathrm{mL}$ nano ICG)+ MMP-2 $(1.0 \mu \mathrm{g} / \mathrm{mL})$, added to the wells. After the hydrogels were formed at $37^{\circ} \mathrm{C}, 100 \mu \mathrm{L}$ fresh culture medium was added into the wells. The groups containing nano ICG were treated with laser $\left(808 \mathrm{~nm}, 0.5 \mathrm{~W} / \mathrm{cm}^{2}, 8\right.$ minutes). After a further 48-hour incubation, the cells were subjected to MTT assays and the cytotoxicity was evaluated.

\section{In vitro scratch assay}

A scratch assay was performed to evaluate the mobility of the SCC-15 cells. Cells were seeded onto 24-well plates $\left(5 \times 10^{3}\right.$ per well). After 24 hours of culture, each well was manually scratched with the tip of a pipette. The NDIMH precursor solutions $(4 \mathrm{mg} / \mathrm{mL}$ nano DOX and $6 \mathrm{mg} / \mathrm{mL}$ nano ICG) were added to the wells. After the hydrogels were formed at $37^{\circ} \mathrm{C}$, fresh culture medium with or without MMP-2 $(1.0 \mu \mathrm{g} / \mathrm{mL})$ was added into the wells and the cells were treated with laser $\left(808 \mathrm{~nm}, 0.5 \mathrm{~W} / \mathrm{cm}^{2}, 8\right.$ minutes). The scratch area was photographed at given time points ( 0 and 24 hours), and the relative migration distances between two cell edges were analyzed using the ImageJ software (NIH).

\section{In vitro invasion assay}

A transwell system ( 24 wells, $8.0 \mu \mathrm{m}$ pore size) was used for the in vitro invasion assay. The upper chamber was coated with $30 \mu \mathrm{L}$ Matrigel, and $1 \times 10^{5}$ cells suspended in $300 \mu \mathrm{L}$ serum-free medium were added. The NDIMH precursor solutions (4 $\mathrm{mg} / \mathrm{mL}$ nano DOX and $6 \mathrm{mg} / \mathrm{mL}$ nano ICG) were added to the wells. After the hydrogels were formed at $37^{\circ} \mathrm{C}$, fresh culture medium in the presence and absence of MMP-2 $(1.0 \mu \mathrm{g} / \mathrm{mL})$ was added into the upper chamber followed by treatment with laser $\left(808 \mathrm{~nm}, 0.5 \mathrm{~W} / \mathrm{cm}^{2}, 8\right.$ minutes). Then, $500 \mu \mathrm{L}$ DMEM containing 20\% FBS was placed into the lower chamber. After incubation for 24 hours, the insert was transferred to a fresh 24-well plate and the non-invading cells were scraped with a wet cotton swab. After rinsing with PBS three times, the lower surface was stained with $0.2 \%$ crystal 
violet for 20 minutes. The stained cells were counted, and the results were statistically analyzed.

\section{Animals and tumor model}

BALB/c nude mice (4-6 weeks old, weight 18-20 g) were purchased from Vital River Laboratory Animal Technology Co. Ltd. (Beijing, China). All animal procedures were performed in compliance with the Guidance Suggestions for the Care and Use of Laboratory Animals and approved by the Institutional Animal Care and Use Committee of Beijing Vital River Laboratory Animal Technology Co. Ltd. To set up the xenograft model, $5 \times 10^{6} \mathrm{SCC}-15$ cells suspended in $100 \mu \mathrm{L}$ of high-protein Matrigel (BD Biosciences, San Jose, CA, USA) were planted by subcutaneous injection into the upper right dorsal area of the mice. Tumor volume was calculated using the following formula: tumor volume $=($ tumor length $) \times(\text { tumor width })^{2} / 2$.

\section{In vivo antitumor test}

The antitumor effects of NDIMH were investigated in nude mice bearing SCC-15 tumors (150-200 $\mathrm{mm}^{3}$ in volume). Tumor-bearing mice were divided into four groups and were intratumorally injected with $50 \mu \mathrm{L}$ normal saline (NS), NDMH (4 mg/mL nano DOX), NIMH (6 mg/mL nano ICG), and NDIMH (4 mg/mL nano DOX and $6 \mathrm{mg} / \mathrm{mL}$ nano ICG), respectively. The groups injected with nano ICG were also treated with laser $\left(808 \mathrm{~nm}, 0.5 \mathrm{~W} / \mathrm{cm}^{2}, 8\right.$ minutes $)$ once per week. Tumor volumes and the general condition of mice were recorded twice weekly, and mice were sacrificed on day 21 after the treatments. Tumors and major organs were harvested for further analysis.

\section{Histological assay}

Tumors and main organs (brain, heart, liver, spleen, lungs, and kidneys) collected from the mice were fixed in 4\% paraformaldehyde. To further evaluate the antitumor efficacy, paraffinembedded tumor sections were stained for TUNEL apoptosis assay (Roche, Beijing, China) and immunohistochemistry assay of Ki67 (Santa Cruz Biotechnology, Santa Cruz, CA, USA) according to the manufacturer's protocols. The cell apoptosis and proliferation of tumors were observed by optical microscopy. In addition, to assess biosafety, tissue sections of major organs were stained with $H \& E$ to observe histopathological changes.

\section{In vivo/ex vivo imaging and biodistribution}

When the tumors reached $150-200 \mathrm{~mm}^{3}$ in volume, the mice were randomly divided into three groups. Mice in each group were intratumorally injected with $50 \mu \mathrm{L}$ free DOX/free ICG mixed aqueous solution or $50 \mu \mathrm{L}$ NDIMH precursor solution (both containing $4 \mathrm{mg} / \mathrm{mL}$ DOX and $6 \mathrm{mg} / \mathrm{mL}$ ICG). The distribution of DOX and ICG was imaged at 10 minutes, 1 hour, 3 hours, 6 hours, 24 hours, 72 hours, and 168 hours after injection using the Maestro EX in vivo imaging system (Maestro 2.0; Cambridge Research \& Instrumentation, Woburn, MA, USA). The DOX signal was obtained with a $480 \mathrm{~nm}$ excitation wavelength and a $580 \mathrm{~nm}$ filter, while that of ICG was obtained with an $805 \mathrm{~nm}$ excitation wavelength and an $835 \mathrm{~nm}$ filter. The mice were euthanized 168 hours after injection, and tumors and major organs (brain, heart, liver, spleen, lungs, and kidneys) were collected for imaging.

\section{Statistical analysis}

All results are shown as mean \pm SD. Statistical analyses were performed using GraphPad Prism 7. Student's $t$-test was used to evaluate the significance of differences between two groups, and one-way ANOVA was used for differences among multiple groups. All quoted $P$-values are two-tailed, and $P<0.05$ was considered significant.

\section{Results \\ Characterization of $\mathrm{MH}$}

A representative picture of the smart hydrogel is given in Figure 1A, and the internal structure, imaged by SEM, is presented in Figure 1B. The smart hydrogel clearly exhibited a highly macroporous structure, which was beneficial for the loading of drugs (the average pore size was $\sim 50 \mu \mathrm{m}$ ).

Excellent biocompatibility and appropriate degradation behavior are very important for biomedical applications of smart hydrogels. The cellular cytotoxicity of the $\mathrm{MH}$ was evaluated by an MTT assay against the SCC-15 cell line. As shown in Figure 1C, SCC-15 cells exposed to the gels showed no difference in terms of proliferation compared with the control group at 24, 48, and 72 hours, confirming the biosafety of the smart hydrogels.

Next, the degradation of the MH was investigated in vivo/ ex vivo, as shown in Figure 1D and E. MHs were placed into the experimental vials, and PBS with or without MMP-2 was added. The smart hydrogel incubated with MMP-2 almost disappeared within 16 days, whereas the control group remained almost unchanged after 16 days of incubation (Figure 1C). These results indicate that the mass loss of the smart hydrogel in the presence of MMP-2 was caused by fast degradation of polypeptide chains and surface erosion. ${ }^{30}$ In vivo gel degradation was also observed in $\mathrm{BALB} / \mathrm{c}$ nude mice bearing SCC-15 tumors after peritumoral and subcutaneous injection of the hydrogels, with normal tissues used as a control. It was found that the gels degraded gradually in the region of the tumors and completely disappeared after 3 weeks. However, the gels in normal tissue degraded much 
A

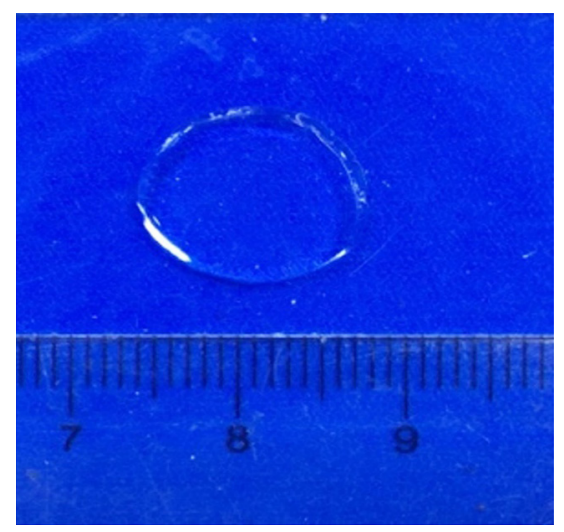

C

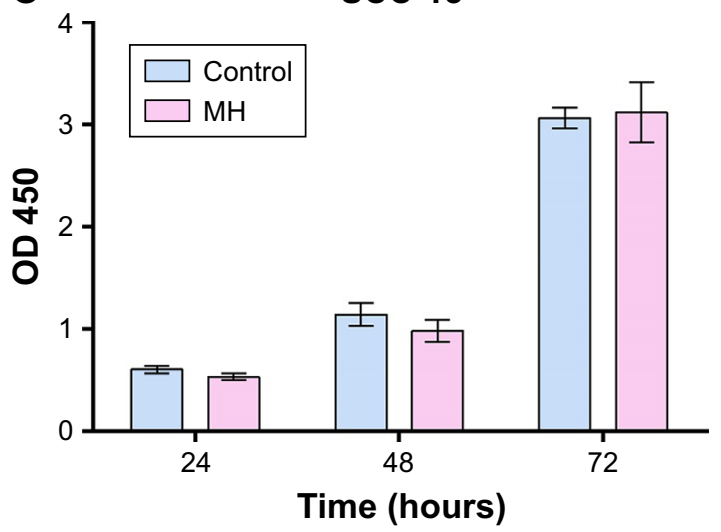

E


SCC-15

7 d
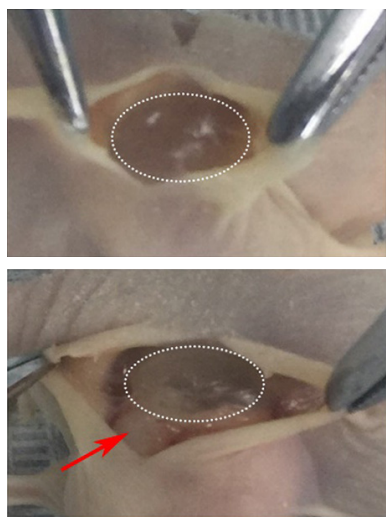

B

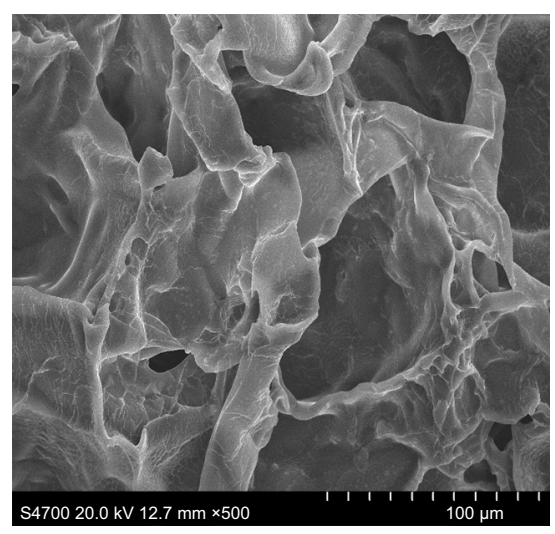

D

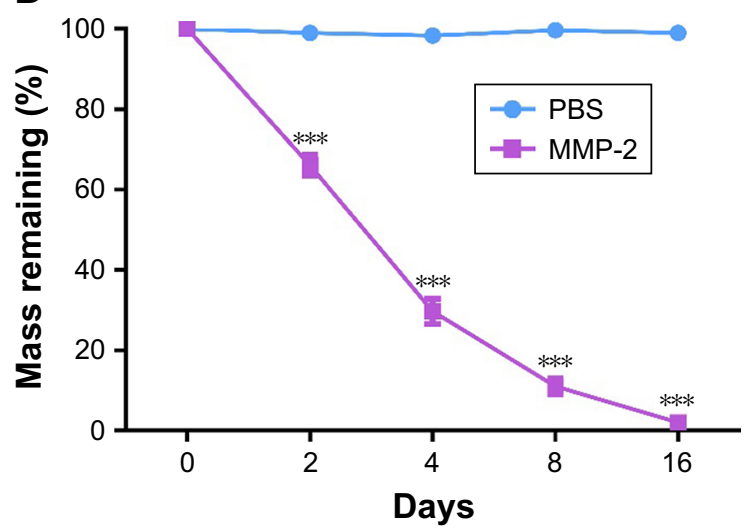

$14 \mathrm{~d}$
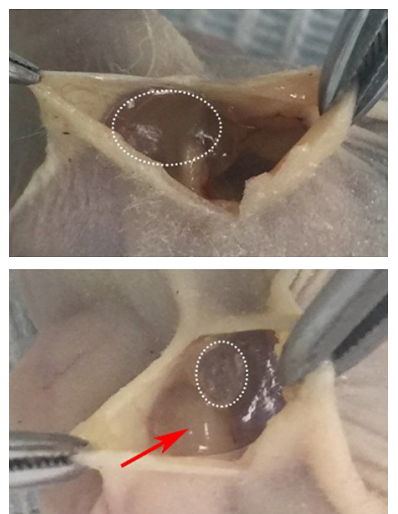

$21 \mathrm{~d}$
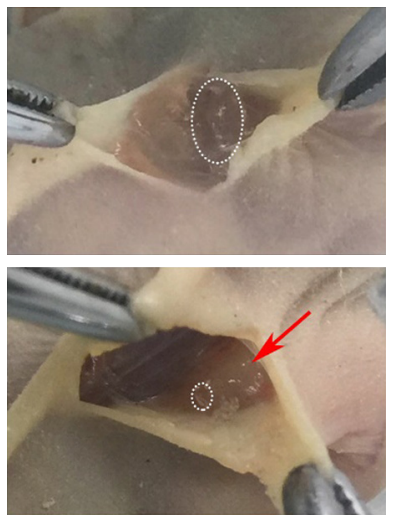

Figure I Characterization of $\mathrm{MH}$.

Notes: (A) General morphological map of $M H$. (B) SEM image of MH (scale bar represents $100 \mu$ m, magnification $\times 500$ ). (C) Cytotoxicity test of MH (mean \pm SD, $n=6$ ). (D) The degradation of $M H$ in vitro (mean $\pm S D, n=3, * * * P<0.00 I$ ). (E) The degradation of $M H$ in vivo (red arrows point to the tumor tissues; gels that remained are circled). Abbreviations: MH, MMP-responsive hydrogel; MMP, matrix metalloproteinase; SEM, scanning electron microscopy.

slower, with $40 \%$ remaining at the end of the experiment (Figure 1D). The above results demonstrate that MH is rapidly degraded in the tumor microenvironment, and confirm its fast response, high sensitivity, and good stability.

\section{Morphology and characterization of NDIMH}

The morphology, size distribution, and zeta potential of the nanodrugs were characterized using TEM and DLS.
As shown in Figure 2A-D, nano DOX/nano ICG was generally spherical in shape with excellent monodispersity and was well distributed in the pores of hydrogels. The average sizes of nano DOX and nano ICG were measured at 81 and $109 \mathrm{~nm}$, respectively, by DLS (Figure 2E and F), while their average surface charges were 1.71 and $3.22 \mathrm{mV}$, respectively (data not shown).

To further evaluate the release of NDIMH, we drew release profiles of the two kinds of nanoparticles (Figure $2 \mathrm{G}$ and $\mathrm{H}$ ). 
Compared with the control group, nano DOX showed a faster release rate and higher concentration in MMP-2 solution. Specifically, as shown in Figure 2G, NDIMH released 50\% nano DOX after 1 day, $70 \%$ after 7 days, and almost $90 \%$ after 14 days. The release profile of nano ICG showed similar trends, indicating the excellent co-encapsulation of nano DOX/nano ICG in the smart hydrogels. Overall, NDIMH exhibited favorable MMP sensitivity and ideal drug release potential.

\section{NDIMH exhibited ideal light-sensitive characteristics}

We assessed the potential phototherapeutic properties of NDIMH through a photothermal efficiency test, intracellular
A

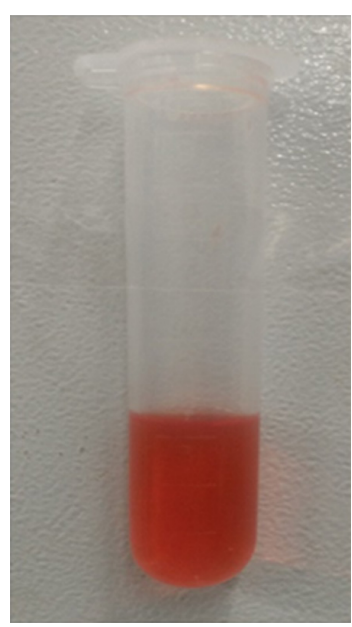

C

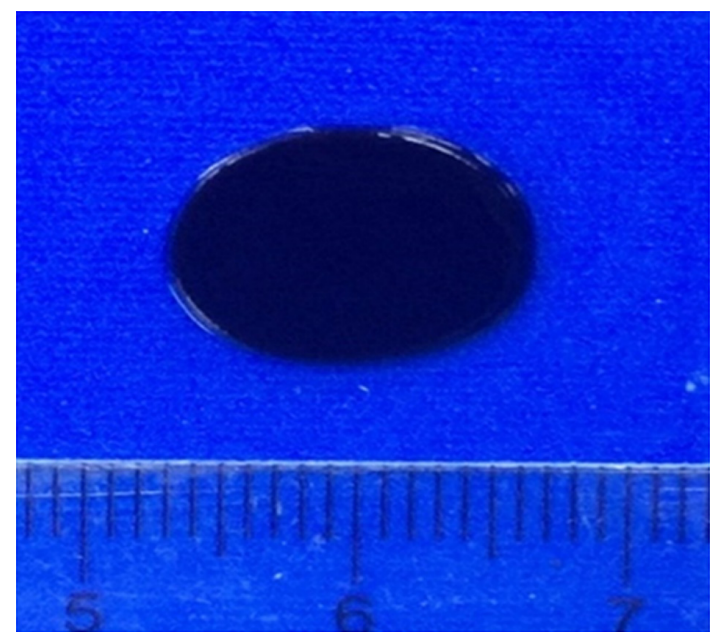

E

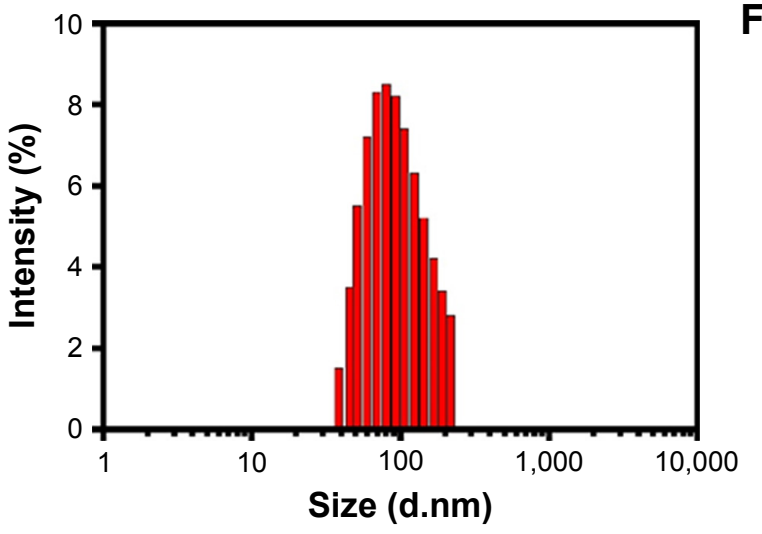

B

D

$\mathbf{F}$
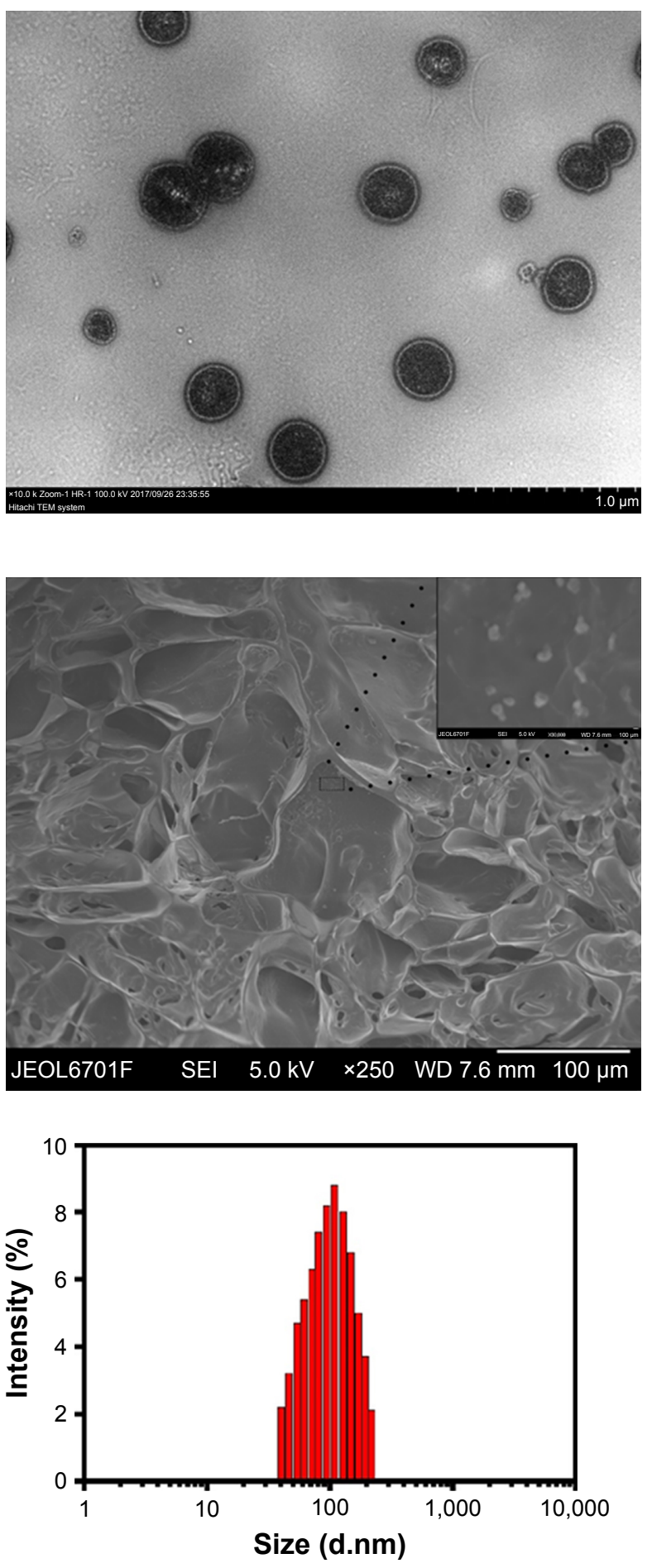

Figure 2 (Continued) 

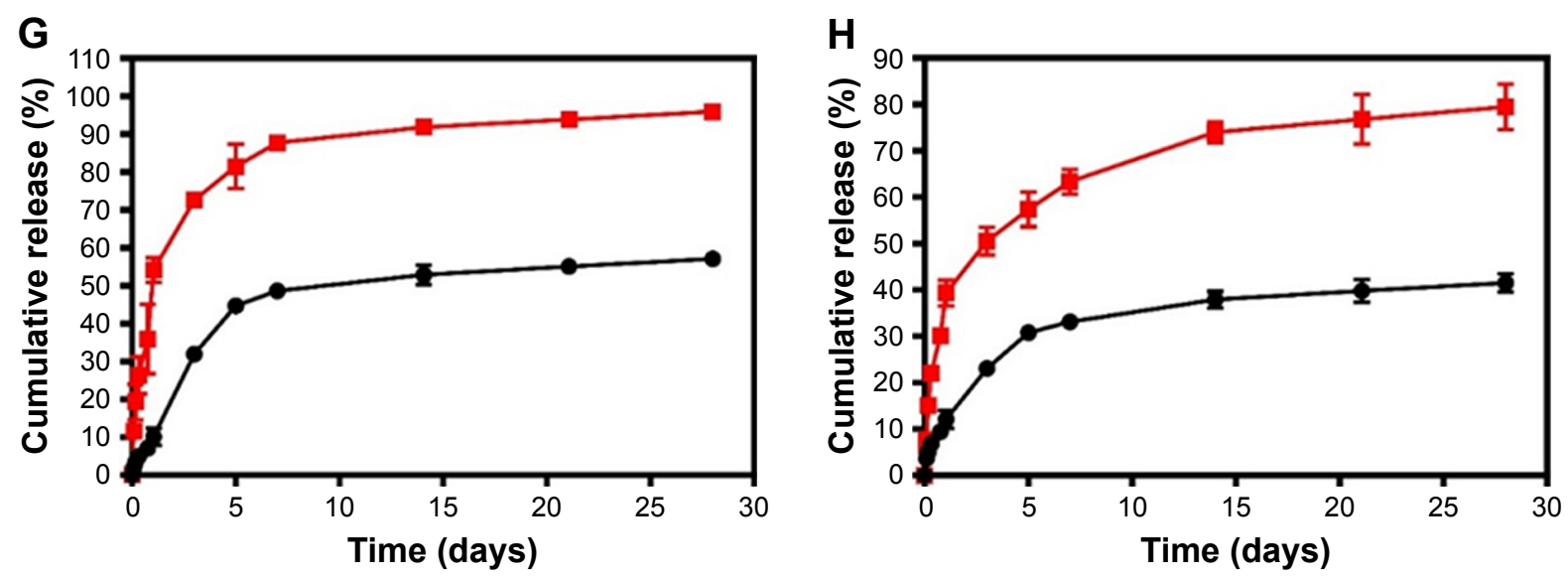

$\rightarrow$ MMP-2 $\rightarrow$ PBS

Figure 2 The morphology and characterization of NDIMH.

Notes: (A) Representative photographs of DOX and ICG nanoparticles dispersed in PBS at ambient temperature (red represents DOX nanoparticles, and green represents ICG nanoparticles). (B) TEM image of nanoparticles (scale bar represents I $\mu \mathrm{m}$, magnification $\times 8,000$ ). (C) General morphological map of NDIMH. (D) SEM image of NDIMH (scale bar represents $100 \mu \mathrm{m}$, magnification $\times 250$ ). (E) The size distribution of DOX nanoparticles. (F) The size distribution of ICG nanoparticles. (G) The nano DOX release profile of NDIMH at varied time points. $(\mathbf{H})$ The nano ICG release profile of NDIMH at varied time points.

Abbreviations: DOX, doxorubicin; ICG, indocyanine green; MMP, matrix metalloproteinase; NDIMH, nano DOX-ICG MMP-responsive hydrogel; SEM, scanning electron microscopy; TEM, transmission electron microscopy.

ROS detection, and an assay of cellular uptake of nanodrugs. First, we used an infrared thermal imaging camera to monitor temperature changes with laser irradiation to evaluate the photothermal properties of NDIMH in vitro. As shown in Figure $3 \mathrm{~A}$ and $\mathrm{C}$, after 10 minutes of laser irradiation $\left(1.0 \mathrm{~W} / \mathrm{cm}^{2}\right)$, the maximum temperatures of PBS, free ICG, and free nano ICG were $36.7^{\circ} \mathrm{C}, 49.3^{\circ} \mathrm{C}$, and $55.5^{\circ} \mathrm{C}$, respectively. Compared with free ICG, free nano ICG showed a
A

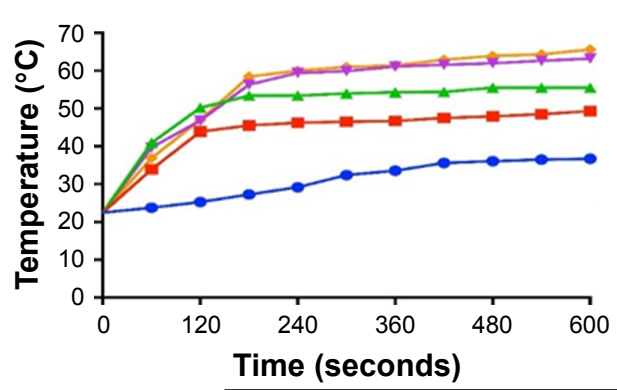

B

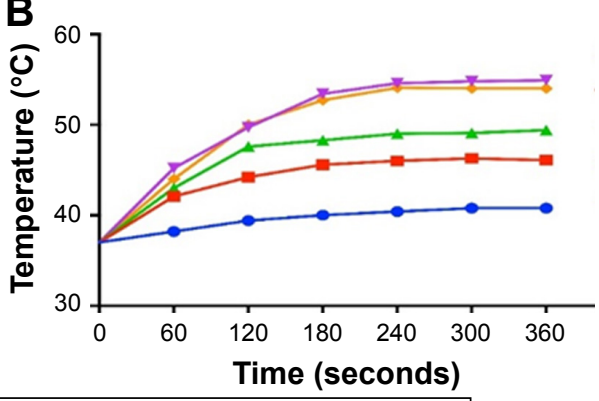
$\rightarrow$ PBS $\rightarrow$ Free ICG $\rightarrow$ Free nano ICG $\rightarrow \mathrm{NIMH} \rightarrow \mathrm{NDIMH}$

C

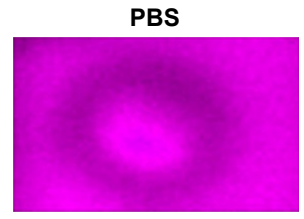

$\mathrm{T}_{\text {max }}: \quad 36.7^{\circ} \mathrm{C}$

D

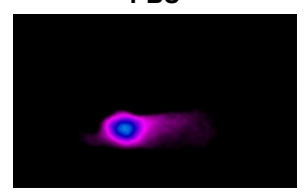

$\mathrm{T}_{\text {max }}: \quad 40.8^{\circ} \mathrm{C}$
Free ICG

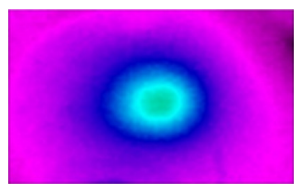

$49.3^{\circ} \mathrm{C}$

Free ICG

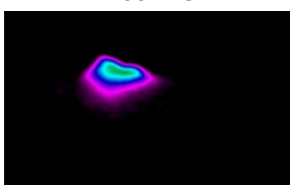

$46.1^{\circ} \mathrm{C}$
Free nano ICG

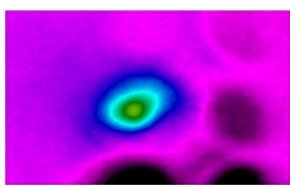

$55.5^{\circ} \mathrm{C}$

Free nano ICG

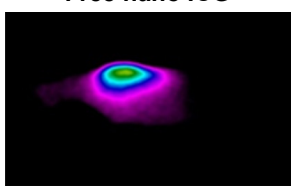

$49.4^{\circ} \mathrm{C}$
NIMH

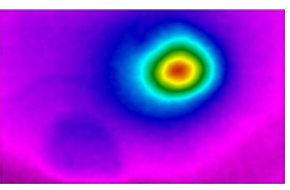

$63.2^{\circ} \mathrm{C}$

NIMH

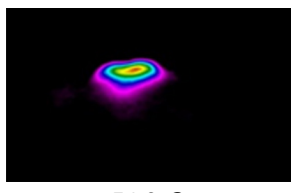

$54.9^{\circ} \mathrm{C}$
NDIMH

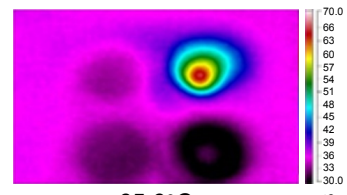

$65.6^{\circ} \mathrm{C}$

NDIMH

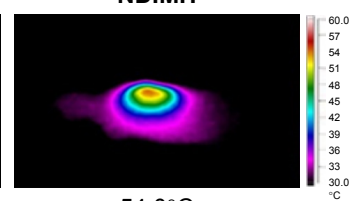

$54.0^{\circ} \mathrm{C}$

Figure 3 (Continued) 
E
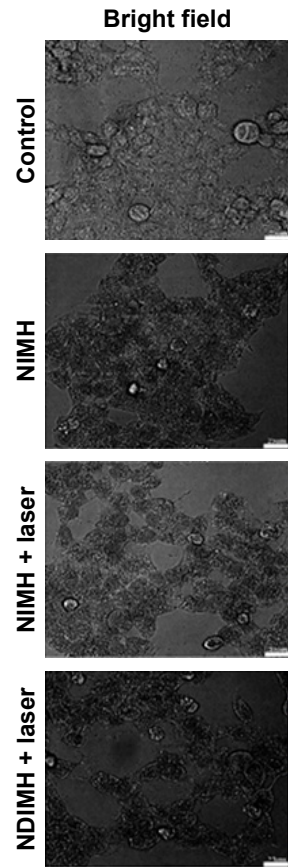

$\mathbf{G}$
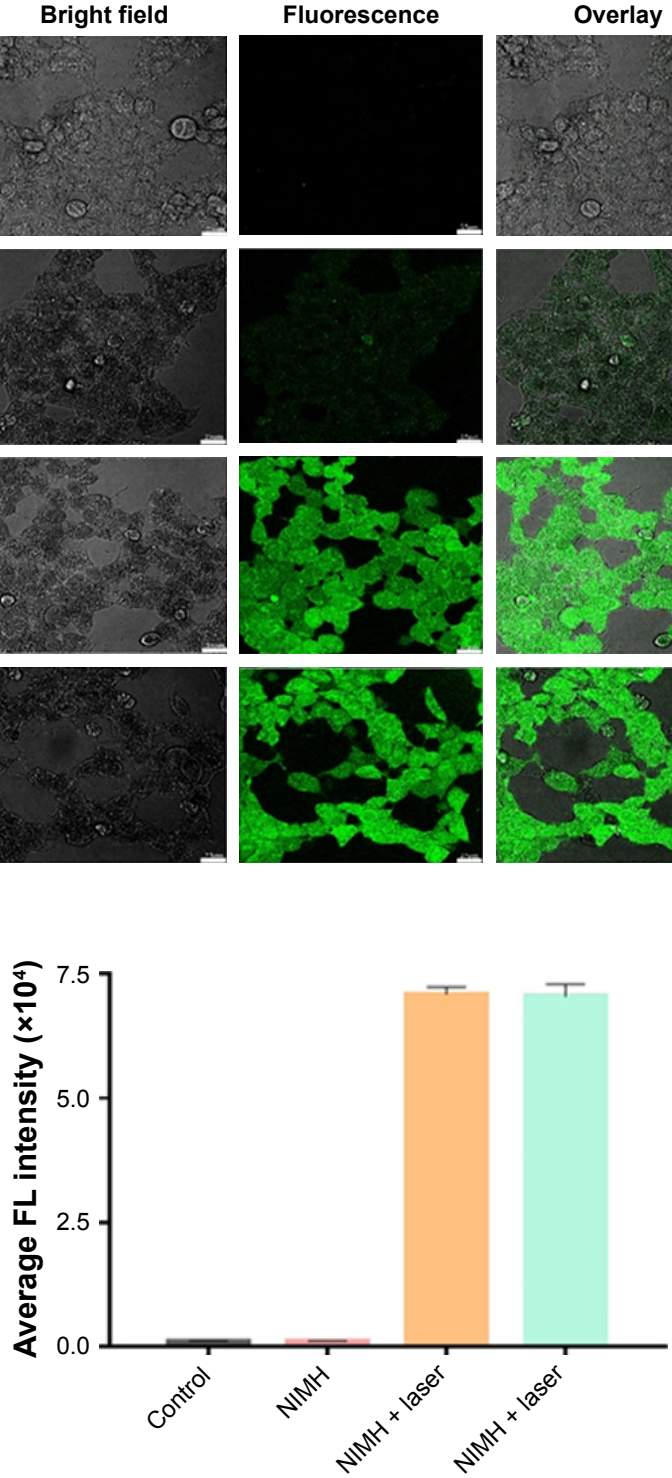

$\mathbf{F}$


H



Figure 3 Evaluation of the photosensitivity properties of NDIMH.

Notes: (A) Maximum temperature profiles of PBS, free ICG, free nano ICG, NIMH, and NDIMH under NIR laser irradiation in vitro. (B) Maximum temperature profiles of the irradiated area of nude mice bearing tumors injected with PBS, free ICG, free nano ICG, NIMH, and NDIMH in vivo. (C) Infrared thermographic maps of a $24-$ well plate after 10 minutes of irradiation. (D) Infrared thermographic maps of mice after intratumoral injection at 6 minutes after laser irradiation. (E) The ROS generation of different formulations (scale bar represents $25 \mu \mathrm{m}$, magnification $\times 630$ ). (F) The cellular uptake of DOX in SCC-I5 (scale bar represents $25 \mu \mathrm{m}$, magnification $\times 500$ ). (G) The quantitative analysis of ROS generation (mean $\pm S D, n=3$ ). $(\mathbf{H})$ The quantitative analysis of cellular uptake of $D O X($ mean $\pm S D, n=3, * * * P<0.00 I)$.

Abbreviations: DOX, doxorubicin; ICG, indocyanine green; NDIMH, nano DOX-ICG matrix metalloproteinase-responsive hydrogel; NDMH, nano DOX matrix metalloproteinase-responsive hydrogel; NIMH, nano ICG matrix metalloproteinase-responsive hydrogel; NIR, near infrared.

greater temperature increase. A possible reason was that the nanodrugs had a much smaller size and therefore were heated more evenly. Interestingly, NIMH and NDIMH had much greater temperature responses than free nano ICG, increasing to $63.2^{\circ} \mathrm{C}$ and $65.6^{\circ} \mathrm{C}$, respectively, under laser irradiation (Figure 3C). This might have been because the excitation thermal radiation was entrapped in the hydrogels, resulting in higher thermal efficiency and lower heat dissipation than in aqueous solutions after laser irradiation. There were no statistical differences between the NIMH and NDIMH groups, demonstrating that nano DOX had no influence on the photothermal properties of NDIMH. Moreover, similar results were obtained in vivo (Figure $3 \mathrm{~B}$ and $\mathrm{D}$ ), indicating that NDIMH possesses good photothermal efficiency.

Second, in order to detect ROS generation, we examined the amount of intracellular ROS by confocal laser FL microscopy via FL intensity. Photosensitizers used in PDT can be activated by an appropriate wavelength of light and transfer the absorbed photon energy to the surrounding molecular oxygen to generate ROS, resulting in cell 
death, vessel damage, and immune activation. ${ }^{16}$ As shown in Figure 3E and G, the FL intensity of ROS was faint or absent in the NIMH group. By contrast, significant FL was observed in the NIMH with $808 \mathrm{~nm}$ laser irradiation group. This suggested that the NIR irritation was a prerequisite for singlet oxygen production. However, there was no difference in FL intensity between the NDIMH + laser group and the $\mathrm{NIMH}+$ laser group, suggesting that nano DOX loading had no influence on ROS generation. Thus, NDIMH with $808 \mathrm{~nm}$ laser irradiation exhibited favorable photodynamic properties, indicating that it could act as a provider of cytotoxic ROS to kill tumor cells.

Finally, to prove that nanoparticles can further promote cellular uptake through the change of their surface characteristics and size, we used CLSM to compare the cellular uptake of free DOX and free nano DOX in SCC-15 cells. As expected, a brighter red FL signal of DOX was present in free nano DOX group than in free DOX group (Figure 3F and $\mathrm{H}$ ). It had been reported that light can affect the characteristics of cells. ${ }^{31,32}$ Besides, we also used CLSM to compare the FL intensities of NDMH and NDIMH + laser to confirm whether light can promote cellular uptake of nano DOX. As shown in Figure 3F, a weak red FL intensity of nano DOX was observed in the cells incubated with NDMH; while a stronger red FL intensity was detected in the cells of the NDIMH + laser group, which demonstrated that laser irradiation could accelerate nano DOX intracellular uptake.

\section{NDIMH can effectively inhibit viability, invasion, and metastasis of SCC-I5 tumor cells}

Proliferation, metastasis, and invasion are three major features of tumor cells. ${ }^{33}$ To investigate the antitumor therapeutic effects of NDIMH in vitro, we cultured SCC-15 cells with different samples and evaluated the treatment efficiency by MTT assay. As shown in Figure 4A, the hydrogel containing either nano ICG or nano DOX exhibited a significantly higher inhibitory rate against SCC-15 cells compared with empty hydrogels. Moreover, NDIMH + laser exhibited a markedly enhanced tumor inhibitory effect compared with NDMH or $\mathrm{NIMH}+$ laser, indicating a synergistic antitumor efficacy in vitro. Notably, NDIMH + laser with MMP-2 showed the highest cytotoxicity against SCC-15 cells. This suggests that $\mathrm{NDIMH}+$ laser in the tumor cell environment could show strong proliferation inhibition of SCC-15 cells.

To confirm whether NDIMH could inhibit the metastasis of SCC-15 cells, we evaluated the effect of NDIMH on the motility of SCC-15 cells using an in vitro scratch assay. As shown in
Figure 4B and C, the group incubated with NDIMH + laser presented the widest migration inhibitory distance between the two cell edges. By contrast, the group incubated with NDIMH + laser + MMP-2 showed no significant difference compared with the control group. A possible reason was that although NDIMH + laser could inhibit the metastasis of tumor cells, MMPs could degrade natural ECM and basement membrane, promoting the metastasis of tumor cells. ${ }^{13}$ We drew similar conclusions from the in vitro invasion assay, which suggested that NDIMH + laser could impair the invasive ability of SCC-15 cells in vitro but could not inhibit the invasion of SCC-15 cells in vitro in the tumor microenvironment (Figure 4D and E).

\section{NDIMH presented good synergistic antitumor efficiency and acceptable biosafety}

A single strategy could not eliminate tumors completely, and the combined therapies have shown great potential for cancer therapy ${ }^{34,35}$ To assess the synergistic antitumor efficiency of NDIMH + laser irradiation $\left(808 \mathrm{~nm}, 0.5 \mathrm{~W} / \mathrm{cm}^{2}\right.$, 8 minutes, once per week), we measured the tumor volumes of each group at given time points. As shown in Figure 5A and $\mathrm{B}$, the tumor volumes of the control groups treated with PBS increased rapidly. By contrast, the group treated with NDMH or NIMH + laser presented much higher inhibition of tumor growth compared with the control group. Notably, the group administrated with NDIMH + laser displayed the greatest antitumor effect, and the tumor growth was completely suppressed within 21 days. The tumor weights were in accordance with the tumor volumes, as shown in Figure 5C.

To further evaluate the antitumor efficacy after treatment with different formulations, the apoptosis of tumor cells was measured by TUNEL assay. As seen in Figure 5E, fewer tumor cells stained brown were observed in control group while larger number of tumor cells stained brown were observed in NDIMH + laser group, which demonstrated the highest apoptosis ratio of tumor cells. ${ }^{36}$ What is more, we also used immunohistochemistry for the cell tumor marker Ki67 to evaluate the antitumor effect of different formulations (Figure 5F). Ki67, a nuclear marker, exists in actively proliferating cells of various tumors. High Ki67 levels are usually associated with poor prognosis. ${ }^{36}$ In our study, we found the NDIMH + laser group had less stained tumor cells than NDMH and $\mathrm{NIMH}+$ laser groups, which indicated better prognosis. These immunohistochemical results confirmed the highest tumor suppression efficiency of NDIMH + laser irradiation.

Side effects caused by antitumor treatments are a great concern in clinical applications, and weight loss is usually 

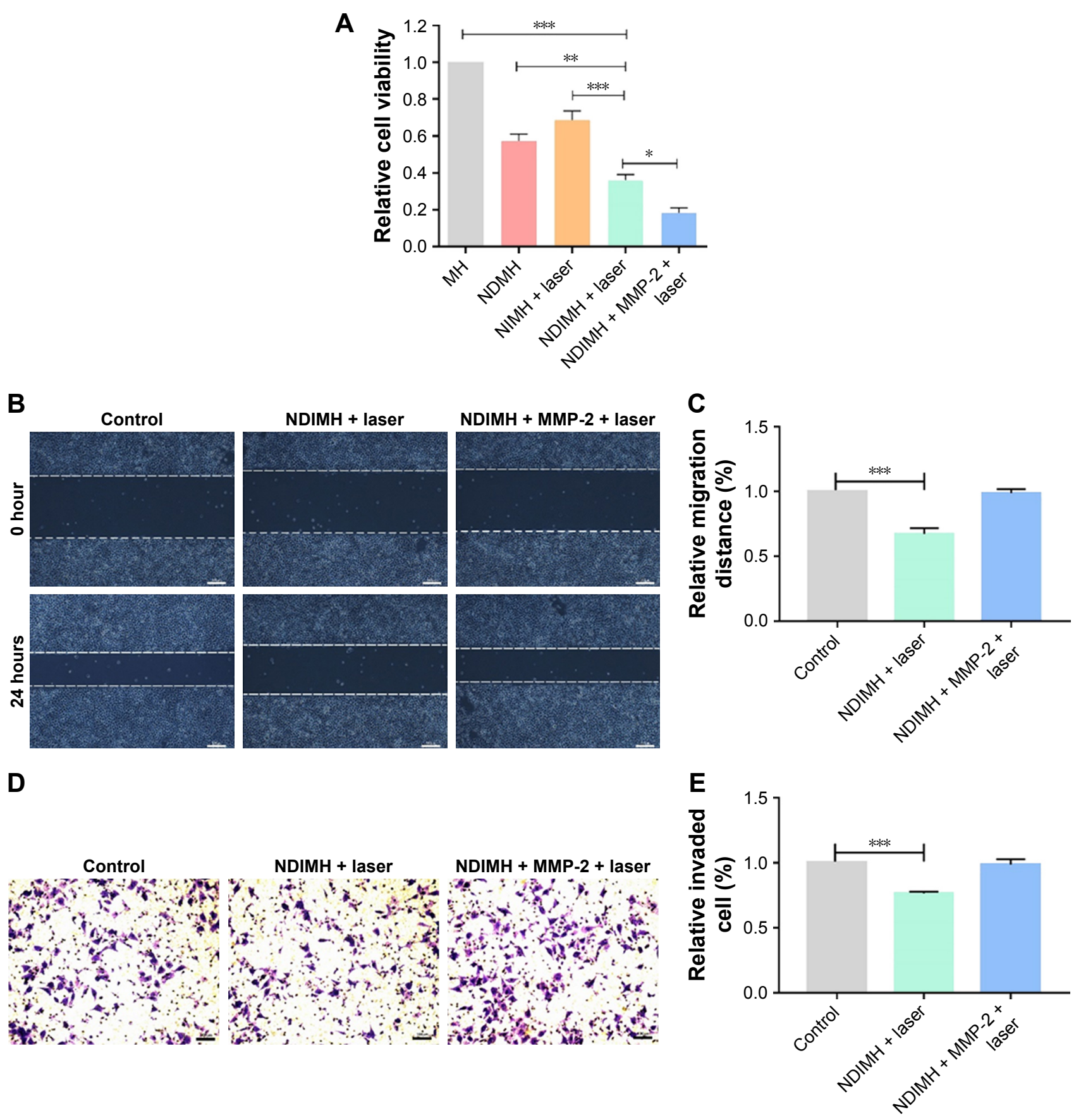

Figure 4 The functions of NDIMH in proliferation, motion, and invasion of SCC-I5 tumor cells in vitro.

Notes: (A) Effects of different formulations on SCC-I5 cells viability at 48 hours (mean $\pm S D, n=6, * P<0.05, * * P<0.01$, $* * * P<0.001$ ). (B) Effects of NDIMH + laser treated with/without MMP-2 on SCC-I 5 cells motion at 24 hours (scale bar: $100 \mu \mathrm{m}$ ). (C) The quantitative analysis of wound healing assay (mean \pm SD, $n=3$, $* * * P<0.00$ I). (D) Effects of NDIMH + laser treated with/without MMP-2 on the invasion of SCC-I5 cells (scale bar: $100 \mu \mathrm{m}$ ). (E) The quantitative analysis of transwell assay (mean \pm SD, $\mathrm{n}=3$, $* * * P<0.001)$.

Abbreviations: MH, MMP-responsive hydrogel; MMP, matrix metalloproteinase; NDIMH, nano doxorubicin-indocyanine green MMP-responsive hydrogel; NDMH, nano doxorubicin MMP-responsive hydrogel; NIMH, nano indocyanine green MMP-responsive hydrogel.

regarded as an indicator of systemic toxicity ${ }^{37}$ Hence, we measured the body weights of mice undergoing different treatments during the whole experimental period (Figure 5D). These data showed no obvious body weight loss in any of the treated groups. At the end of the tests, the major organs were harvested and H\&E stained for histopathological analysis. Since nano DOX and nano ICG were released from the smart hydrogels slowly, low systemic toxicity of the treatments was expected. As shown in Figure 5G, no abnormalities were observed in the main organs. 
These results indicated the good tolerance and biosafety of all treatment formulations.

\section{In vivo imaging and biodistribution of NDIMH}

Since DOX and ICG have different excitation and emission wavelengths, we were able to detect the FL of nano DOX and nano ICG of NDIMH using an in vivo/ex vivo imaging system at specific time points.

A

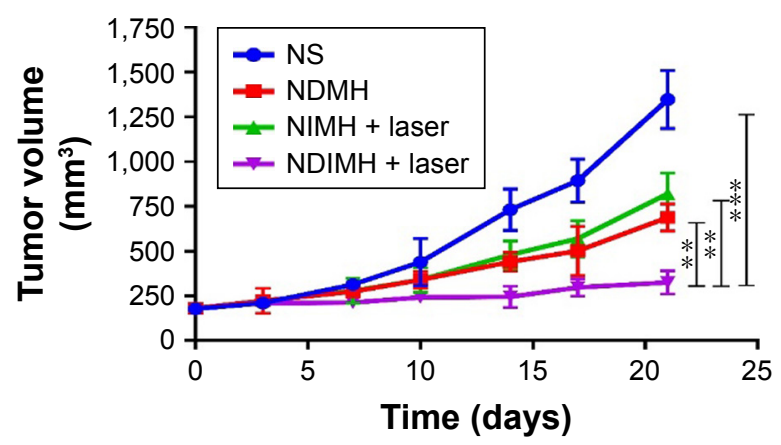

C

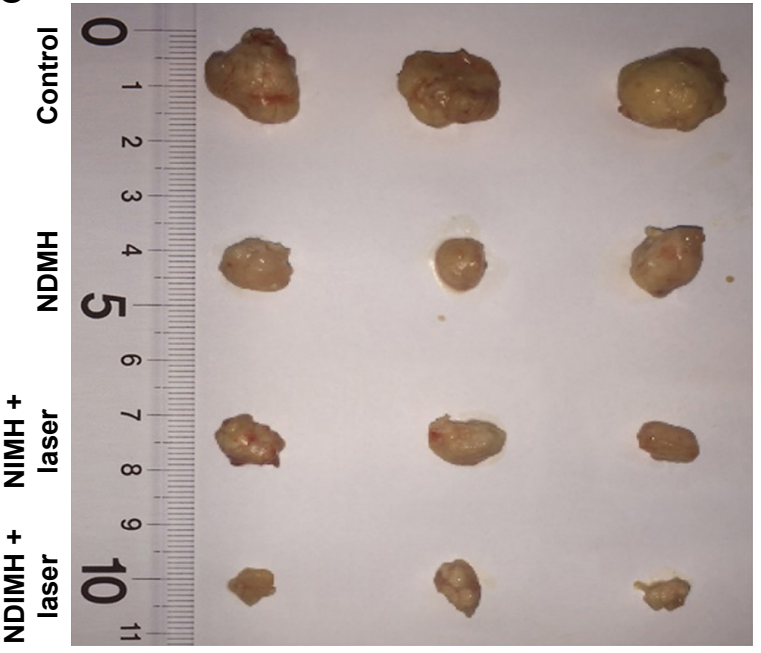

E

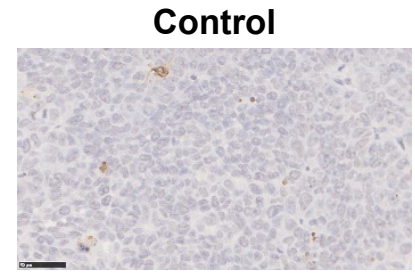

$\mathbf{F}$

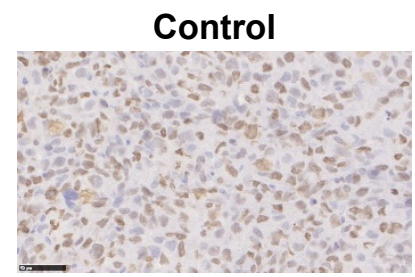

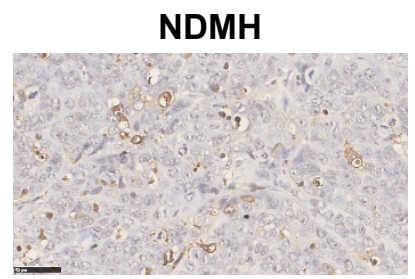

NDMH

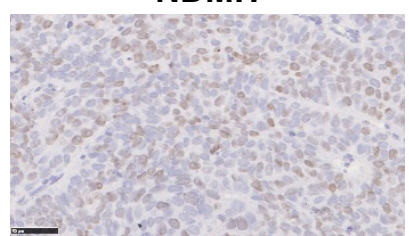



D



$\mathrm{NIMH}+$ laser

NDIMH + laser
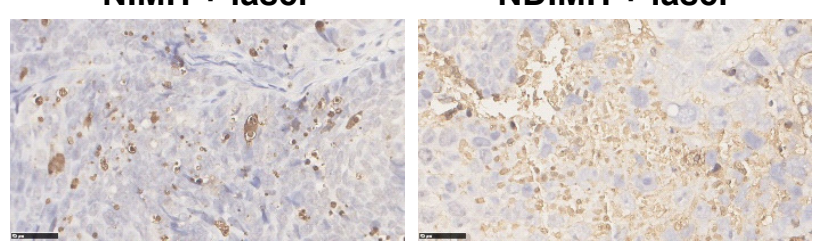

$\mathrm{NIMH}+$ laser

NDIMH + laser

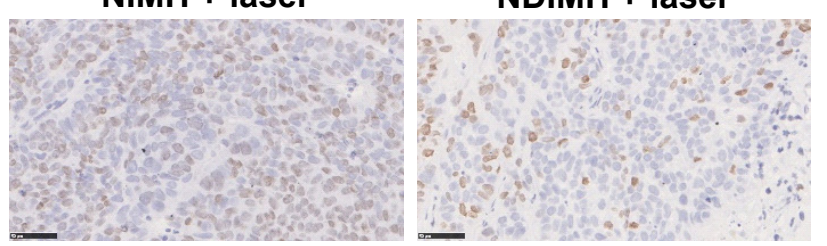



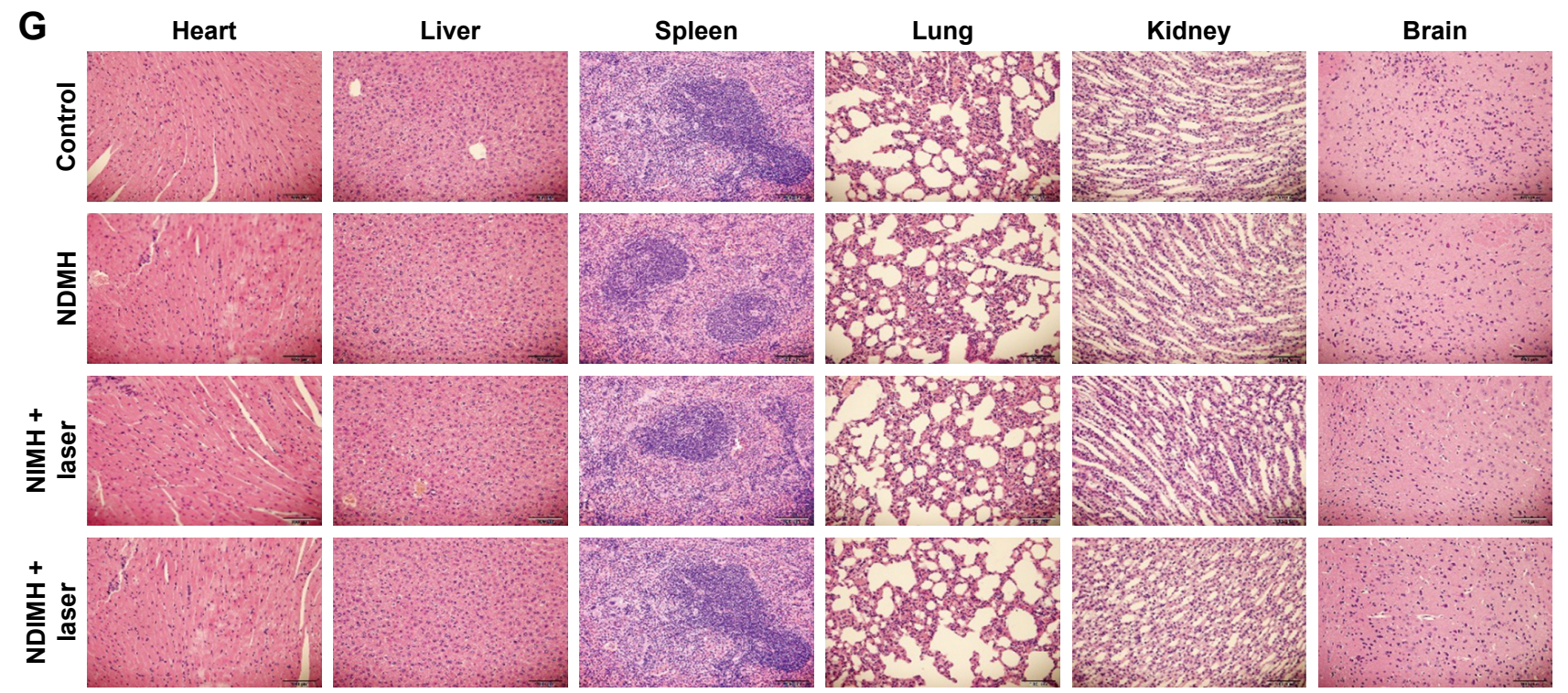

Figure 5 Antitumor effects and biosafety evaluation of NDIMH in vivo.

Notes: (A) SCC-15 tumor growth curves of different groups after intratumoral injection up to 21 days (mean \pm SD, $n=3$, $* * P<0.01$, $* * * P<0.00 I$ ). (B) SCC-I5 tumor mass histogram of different groups $2 \mathrm{I}$ days after treatments (mean $\pm S D, n=3, * P<0.05, * * P<0.01$, $* * * P<0.00 I$ ). (C) The photograph of excised tumors 2 I days after treatments. (D) The body weight changes of the mice during treatments (mean $\pm S D, n=3$ ). (E) TUNEL apoptosis assay of tumor sections 21 days after treatments. Cells stained brown indicated apoptotic cells (scale bar represents $50 \mu \mathrm{m}$, magnification $\times 40$ ). (F) Immunohistochemical staining for Ki67 expression of tumor sections 21 days after treatments. Cells stained brown indicated proliferating cells (scale bar represents $50 \mu \mathrm{m}$, magnification $\times 40$ ). (G) Histological sections of the main organs (brain, heart, liver, spleen, lungs, and kidneys) were stained by H\&E. Abbreviations: NDIMH, nano doxorubicin-indocyanine green matrix metalloproteinase-responsive hydrogel; NDMH, nano doxorubicin matrix metalloproteinaseresponsive hydrogel; NIMH, nano indocyanine green matrix metalloproteinase-responsive hydrogel; NS, normal saline.

Afterward, the mice were sacrificed and tumors and major organs were collected for ex vivo imaging analysis 168 hours after injection. Both nano DOX and nano ICG were found to be distributed in tumors and organs in the NDIMH group, with much higher FL accumulation than in the free group
(Figure 6C and D), suggesting that NDIMH has excellent sustained drug-release properties.

Notably, in the NDIMH group, the FL signal of nano ICG was stronger than that of nano DOX at each time point, demonstrating that ICG possesses an excellent property of
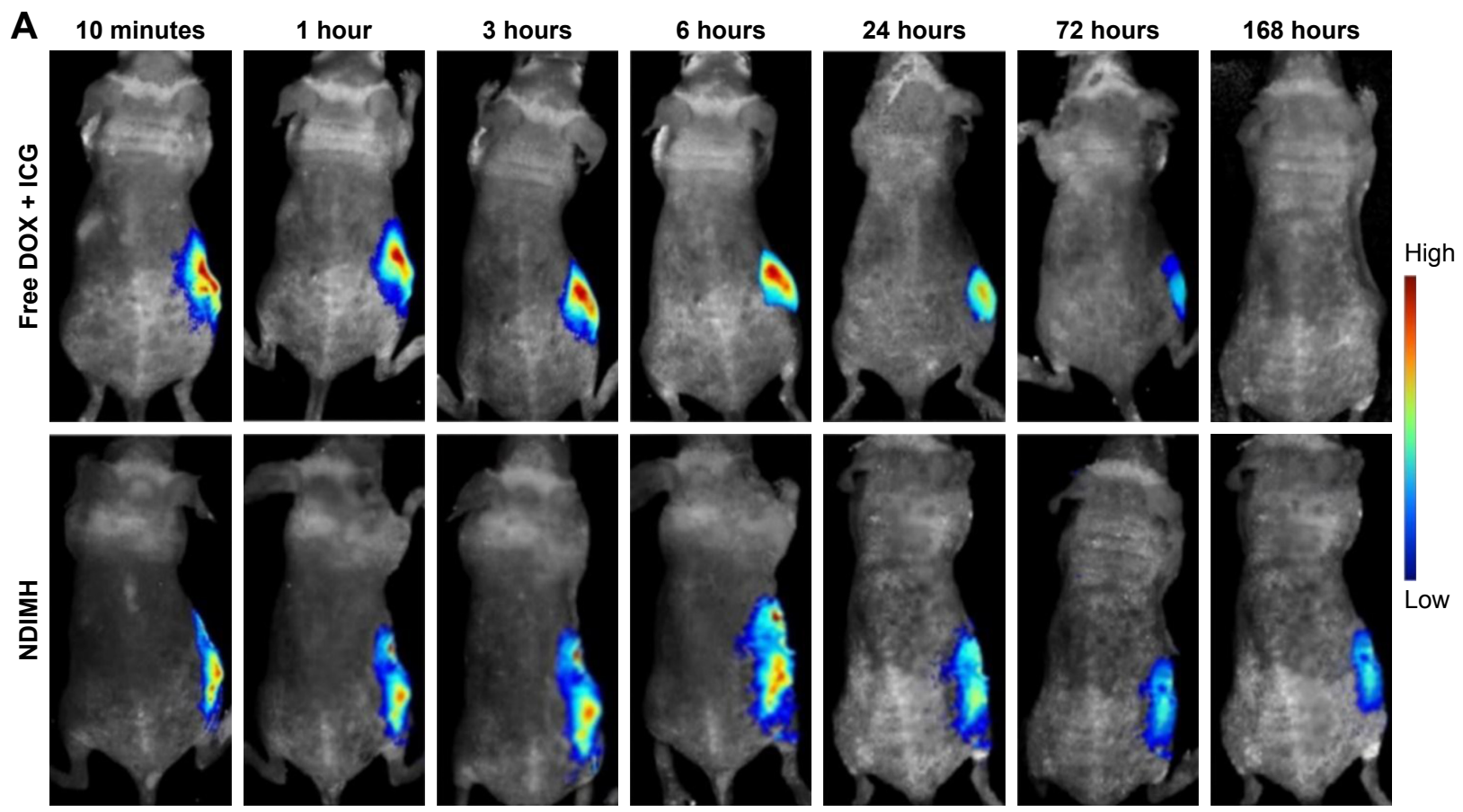

Figure 6 (Continued) 

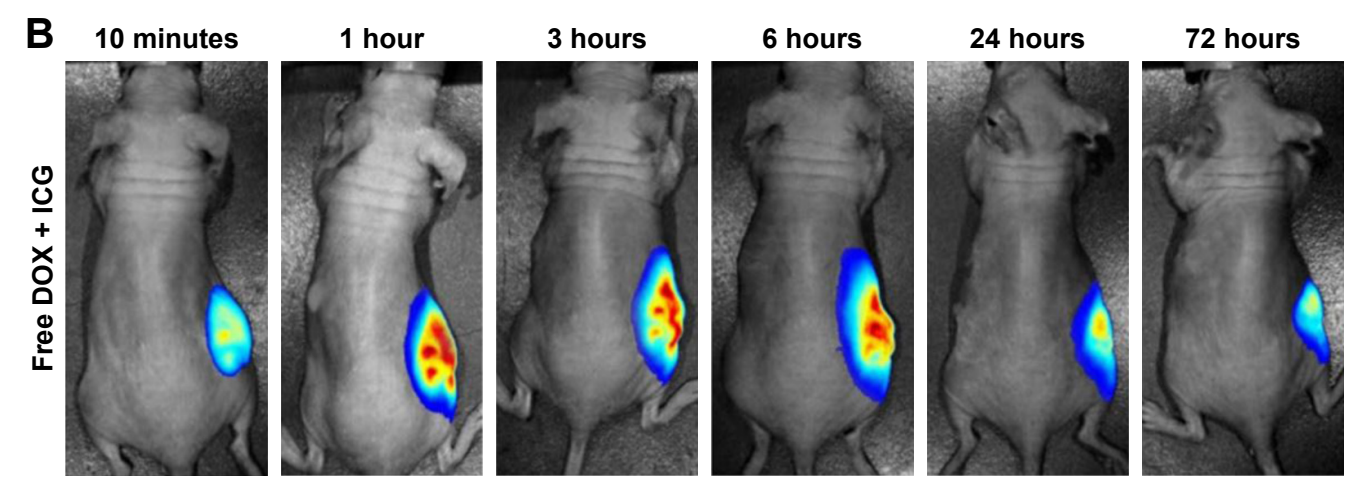

168 hours
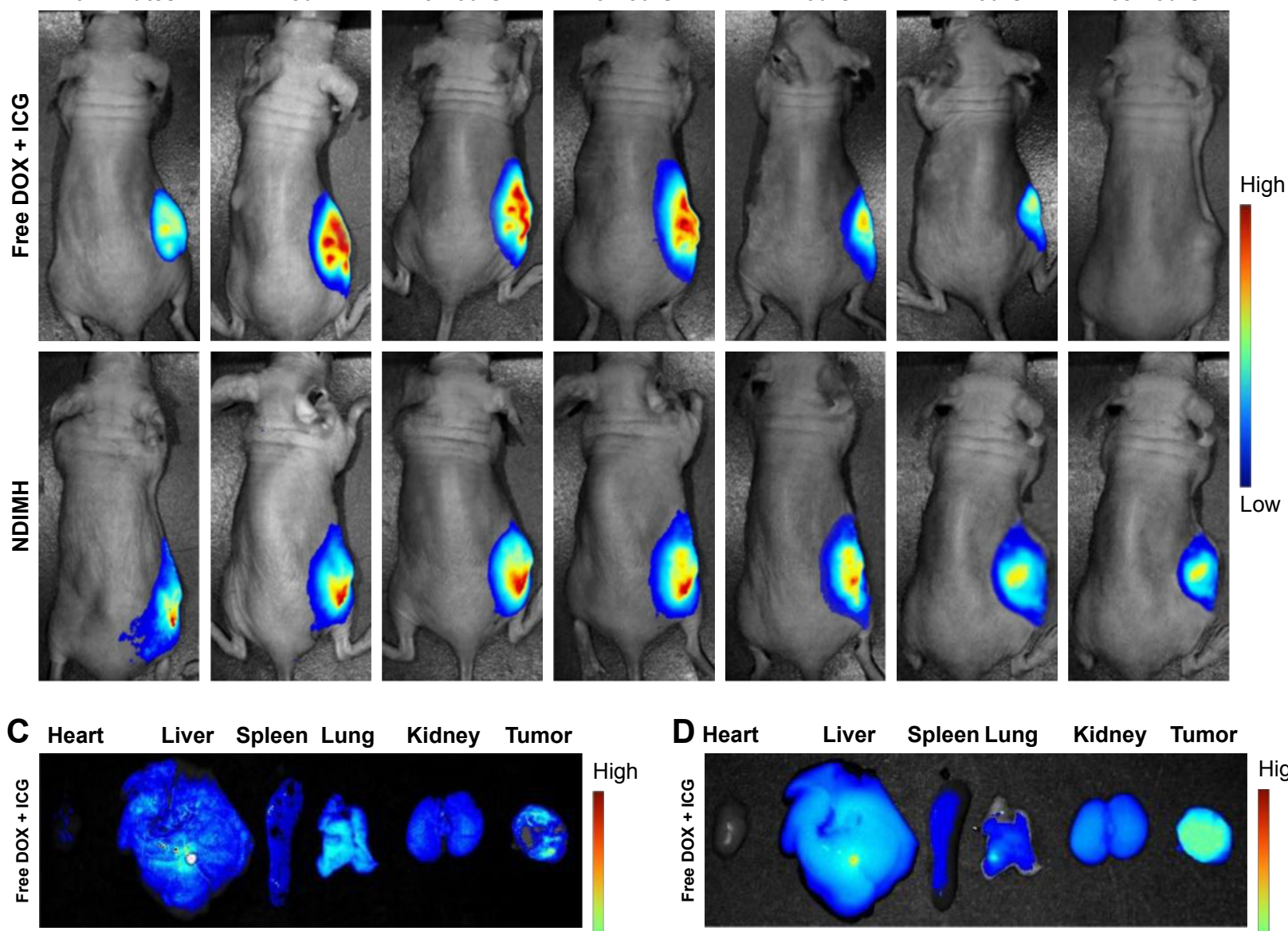

\section{Heart}

\section{Liver}

Spleen Lung

Kidney Tumor
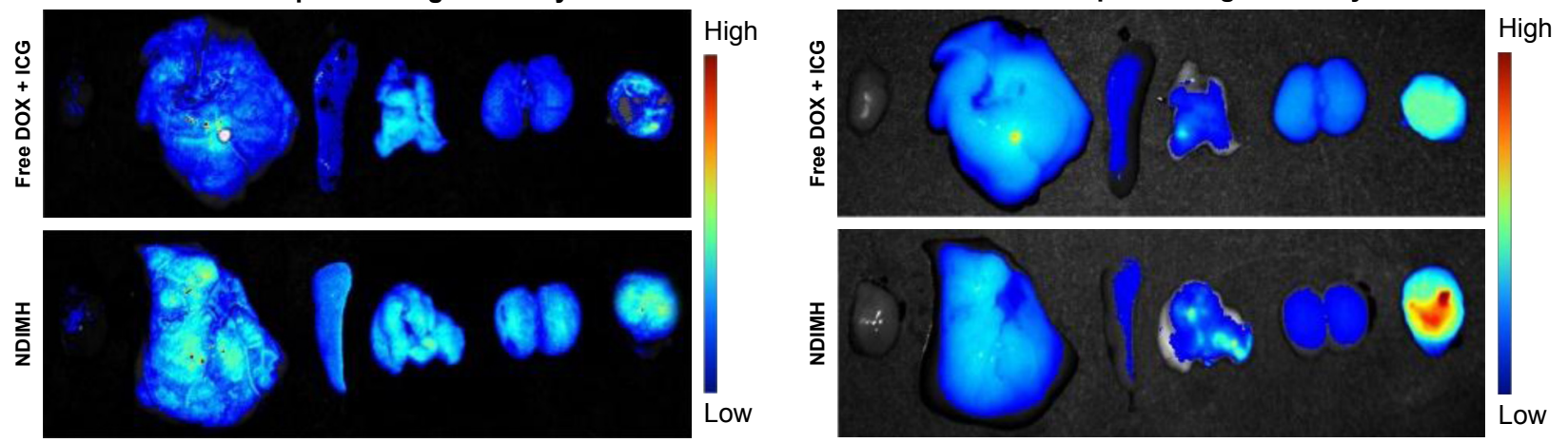

Figure 6 In vivo FL imaging and biodistribution of DOX/ICG in mice bearing SCC-I5 tumors after intratumoral injection of free DOX + ICG or NDIMH.

Notes: (A) Time-lapse DOX FL of the whole body of mice. (B)Time-lapse ICG FL of the whole body of mice. (C) DOX FL intensity of major organs and tumors after 21 days of administration. (D) ICG FL intensity of major organs and tumors after 21 days of administration.

Abbreviations: DOX, doxorubicin; FL, fluorescence; ICG, indocyanine green; NDIMH, nano DOX-ICG matrix metalloproteinase-responsive hydrogel.

FL imaging which is the reason for its wide use in cancer imaging and diagnosis. . $^{38,39}$

\section{Discussion}

In this study, we combined cancer targeting, nanotechnology, chemophototherapy, and FL imaging to successfully design a new drug delivery system, NDIMH, for sustained release of nano DOX and nano ICG in the tumor microenvironment. The antitumor efficiency was confirmed in vivo/in vitro through physiochemical tests, biological activity tests, and general pharmacological tests. To our knowledge, this is the first time that nano DOX and nano ICG have been loaded into an MMP-responsive HA hydrogel for the chemophototherapy of HNSCC (China patent: 201810815535.2).
Cancer therapy is a long-duration and complicated process, and a single strategy is not usually adequate to eliminate tumors completely. ${ }^{34,35}$ Chemophototherapy has emerged as a promising treatment option for solid tumors. ${ }^{18}$ Some studies have shown that a combination of DOX-based chemotherapy and ICG-based phototherapy can enhance antitumor efficacy and minimize systemic toxicity. ${ }^{40-43} \mathrm{DOX}$ is a broad-spectrum antitumor antibiotic that can inhibit the synthesis of RNA and DNA. We utilized its autofluorescence for real-time monitoring of its biodistribution in vivo after administration. ICG is a cyanine compound that displays excellent FL under NIR irradiation. ${ }^{22}$ Interestingly, we found that ICG could promote the cellular uptake of DOX. This may be attributed to a change in cell membrane characteristics after light exposure. ${ }^{31}$ 
Drug delivery systems based on nanotechnology have increasingly attracted attention. Nanosizing a formulation can increase the drug dissolution rate and thereby promote drug absorption and bioavailability. ${ }^{44}$ The size and surface charges of nanoparticles are essential parameters that determine their pharmacokinetics and biodistribution. ${ }^{44,45}$ Generally, the size range of $30-200 \mathrm{~nm}$ is preferable, being large enough to avoid leakage into capillaries, but also small enough to avoid mononuclear phagocyte system clearance. ${ }^{46}$ In addition, the surface charge of nanoparticles can affect their uptake by tumor cells. Previous studies have shown that positively charged formulations have a higher rate of cell uptake compared with neutral or negatively charged nanoparticles. ${ }^{47}$ In our study, we synthesized nano DOX and nano ICG using solvent-antisolvent method, and the parameters of the nanoparticles coincided with these standards. What is more, the nano DOX exhibited higher cellular uptake and nano ICG displayed stronger photothermal properties than the regular ones. Despite the potential advantages, there are limited numbers of nanomedical products for tumor-targeted therapies on the market, such as Oncaspar, Doxil/Caelyx, Daunoxome, DepoCyt, Myocet, and Abraxane. ${ }^{48-53}$

Hydrogels are three-dimensional networks of cross-linked hydrophilic polymer chains. Localized therapy with injectable hydrogels can provide a sustained and controlled drug release while minimizing systemic adverse effects. ${ }^{54,55}$ Achieving controlled release of the loaded drugs into tumor site and making different kinds of drugs exert synergistic antitumor effects is a big challenge. Given the high expression rate of MMPs in tumor tissues, ${ }^{11,12}$ we synthesized NDIMH which could release nano DOX and nano ICG continuously in the presence of MMPs. In release assay in vitro, NDIMH showed sensitivity and ideal drug release potential. From the FL imaging in vivo, it was found that nano DOX and nano ICG of NDIMH had a sustained release and greatly enhanced the retention of nanodrugs at the tumor site. Besides, NDIMH with $808 \mathrm{~nm}$ NIR irradiation displayed synergistic antitumor efficiency in in vivo/in vitro tumor inhibition test.

\section{Conclusion}

Thus, we developed a new drug delivery system and showed that the intratumoral injection of NDIMH combined with $808 \mathrm{~nm}$ NIR irradiation could be a promising chemophototherapy alternative for HNSCC.

\section{Acknowledgments}

This study was supported by grants from the National Natural Science Foundation of China (Nos 51472270, 81703003,
51472270, 51303009, 21476018, and 81602393), China Postdoctoral Science Foundation Funded Project (Nos 2017M623395 and 2018T111143), and Wu Jieping Medical Foundation (No. 320.6799.1140).

\section{Disclosure}

The authors report no conflicts of interest in this work.

\section{References}

1. Siegel RL, Miller KD, Jemal A. Cancer statistics, 2017. CA Cancer J Clin. 2017;67(1):7-30.

2. Bagan J, Sarrion G, Jimenez Y. Oral cancer: clinical features. Oral Oncol. 2010;46(6):414-417.

3. Kraus S, Miller BH, Swinehart JM, et al. Intratumoral chemotherapy with fluorouracil/epinephrine injectable gel: a nonsurgical treatment of cutaneous squamous cell carcinoma. J Am Acad Dermatol. 1998;38(3): 438-442.

4. Vissink A, Jansma J, Spijkervet FK, Burlage FR, Coppes RP. Oral sequelae of head and neck radiotherapy. Crit Rev Oral Biol Med. 2003; 14(3):199-212.

5. Luo D, Carter KA, Miranda D, Lovell JF. Chemophototherapy: an emerging treatment option for solid tumors. $A d v$ Sci. 2017;4(1):1600106.

6. Carvalho AL, Nishimoto IN, Califano JA, Kowalski LP. Trends in incidence and prognosis for head and neck cancer in the United States: a sitespecific analysis of the SEER database. Int J Cancer. 2005;114(5):806-816.

7. Clayman GL, Dreiling LK. Injectable modalities as local and regional strategies for head and neck cancer. Hematol Oncol Clin North Am. 1999;13(4):787-810.

8. Norouzi M, Nazari B, Miller DW. Injectable hydrogel-based drug delivery systems for local cancer therapy. Drug Discov Today. 2016;21(11): 1835-1849.

9. Mura S, Nicolas J, Couvreur P. Stimuli-responsive nanocarriers for drug delivery. Nat Mater. 2013;12(11):991-1003.

10. Timko BP, Dvir T, Kohane DS. Remotely triggerable drug delivery systems. Adv Mater. 2010;22(44):4925-4943.

11. Egeblad M, Werb Z. New functions for the matrix metalloproteinases in cancer progression. Nat Rev Cancer. 2002;2(3):161-174.

12. Coussens LM, Fingleton B, Matrisian LM. Matrix metalloproteinase inhibitors and cancer: trials and tribulations. Science. 2002;295(5564): 2387-2392.

13. Yao Q, Kou L, Tu Y, Zhu L. MMP-responsive "Smart" drug delivery and tumor targeting. Trends Pharmacol Sci. 2018;39(8):766-781.

14. Rigual NR, Thankappan K, Cooper M, et al. Photodynamic therapy for head and neck dysplasia and cancer. Arch Otolaryngol Head Neck Surg. 2009;135(8):784-788.

15. Paiva MB, Bublik M, Castro DJ, et al. Intratumor injections of cisplatin and laser thermal therapy for palliative treatment of recurrent cancer. Photomed Laser Surg. 2005;23(6):531-535.

16. Mimikos C, Shafirstein G, Arshad H. Current state and future of photodynamic therapy for the treatment of head and neck squamous cell carcinoma. World J Otorhinolaryngol Head Neck Surg. 2016;2(2): 126-129.

17. Yue X, Zhang Q, Dai Z. Near-infrared light-activatable polymeric nanoformulations for combined therapy and imaging of cancer. Adv Drug Deliv Rev. 2017;115:155-170.

18. Palumbo MN, Cervantes $\mathrm{O}$, Eugênio $\mathrm{C}$, et al. Intratumor cisplatin nephrotoxicity in combined laser-induced thermal therapy for cancer treatment. Lasers Surg Med. 2017;49(8):756-762.

19. Chibber S, Farhan M, Hassan I, Naseem I. White light-mediated Cu (II)-5FU interaction augments the chemotherapeutic potential of 5-FU: an in vitro study. Tumour Biol. 2011;32(5):881-892.

20. Li L, Liu T, Fu C, Liu H, Tan L, Meng X. Multifunctional silica-based nanocomposites for cancer nanotheranostics. J Biomed Nanotechnol. 2014;10(9):1784-1809. 
21. Chibber S, Farhan M, Hassan I, Naseem I. Novel aspect of chemophototherapy in treatment of cancer. Tumour Biol. 2012;33(3):701-706.

22. Porcu EP, Salis A, Gavini E, Rassu G, Maestri M, Giunchedi P. Indocyanine green delivery systems for tumour detection and treatments. Biotechnol Adv. 2016;34(5):768-789.

23. Hayek ER, Speakman E, Rehmus E. Acute doxorubicin cardiotoxicity. N Engl J Med. 2005;352(23):2456-2457.

24. Carter SK, Blum RH. New chemotherapeutic agents - bleomycin and adriamycin. CA Cancer J Clin. 1974;24(6):322-331.

25. Kanapathipillai M, Brock A, Ingber DE. Nanoparticle targeting of anti-cancer drugs that alter intracellular signaling or influence the tumor microenvironment. Adv Drug Deliv Rev. 2014;79-80(80):107-118.

26. Wei L, Cai C, Lin J, Chen T. Dual-drug delivery system based on hydrogel/micelle composites. Biomaterials. 2009;30(13):2606-2613.

27. Wu Z, Zou X, Yang L, et al. Thermosensitive hydrogel used in dual drug delivery system with paclitaxel-loaded micelles for in situ treatment of lung cancer. Colloids Surf B Biointerfaces. 2014;122:90-98.

28. Hu J, Chen Y, Li Y, Zhou Z, Cheng Y. A thermo-degradable hydrogel with light-tunable degradation and drug release. Biomaterials. 2017; 112:133-140.

29. Lei Y, Gojgini S, Lam J, Segura T. The spreading, migration and proliferation of mouse mesenchymal stem cells cultured inside hyaluronic acid hydrogels. Biomaterials. 2011;32(1):39-47.

30. Moon HJ, Choi BG, Park MH, Joo MK, Jeong B. Enzymatically degradable thermogelling poly(alanine-co-leucine)-poloxamer-poly(alanineco-leucine). Biomacromolecules. 2011;12(4):1234-1242.

31. Borlon C, Debacq-Chainiaux F, Hinrichs C, Scharffetter-Kochanek K, Toussaint $\mathrm{O}$, Wlaschek $\mathrm{M}$. The gene expression profile of psoralen plus UVA-induced premature senescence in skin fibroblasts resembles a combined DNA-damage and stress-induced cellular senescence response phenotype. Exp Gerontol. 2007;42(9):911-923.

32. Cheng L, Wang C, Feng L, Yang K, Liu Z. Functional nanomaterials for phototherapies of cancer. Chem Rev. 2014;114(21):10869-10939.

33. Hermann PC, Huber SL, Herrler T, et al. Distinct populations of cancer stem cells determine tumor growth and metastatic activity in human pancreatic cancer. Cell Stem Cell. 2007;1(3):313-323.

34. You J, Zhang P, Hu F, et al. Near-infrared light-sensitive liposomes for the enhanced photothermal tumor treatment by the combination with chemotherapy. Pharm Res. 2014;31(3):554-565.

35. Woodcock J, Griffin JP, Behrman RE. Development of novel combination therapies. N Engl J Med. 2011;364(11):985-987.

36. Zhou Y, Hu W, Chen P, et al. Ki67 is a biological marker of malignant risk of gastrointestinal stromal tumors. Medicine. 2017;96(34):e7911.

37. Lee H, Fonge H, Hoang B, Reilly RM, Allen C. The effects of particle size and molecular targeting on the intratumoral and subcellular distribution of polymeric nanoparticles. Mol Pharm. 2010;7(4):1195-1208.

38. Fujiwara M, Mizukami T, Suzuki A, Fukamizu H. Sentinel lymph node detection in skin cancer patients using real-time fluorescence navigation with indocyanine green: preliminary experience. J Plast Reconstr Aesthet Surg. 2009;62(10):e373-e378.
39. Ishizawa T, Fukushima N, Shibahara J, et al. Real-time identification of liver cancers by using indocyanine green fluorescent imaging. Cancer. 2009;115(11):2491-2504

40. Tang Y, Mcgoron AJ. Combined effects of laser-ICG photothermotherapy and doxorubicin chemotherapy on ovarian cancer cells. J Photochem Photobiol B. 2009;97:138-144.

41. Zheng M, Yue C, Ma Y, et al. Single-step assembly of DOX/ICG loaded lipid - polymer nanoparticles for highly effective chemo-photothermal combination therapy. ACS Nano. 2013;7(3):2056-2067.

42. Zhao P, Zheng M, Luo Z, et al. NIR-driven smart theranostic nanomedicine for on-demand drug release and synergistic antitumour therapy. Sci Rep. 2015;5(1):14258

43. Chen Y, Li H, Deng Y, Sun H, Ke X, Ci T. Near-infrared light triggered drug delivery system for higher efficacy of combined chemophotothermal treatment. Acta Biomater. 2017;51:374-392.

44. de Jong WH, Borm PJ. Drug delivery and nanoparticles: applications and hazards. Int J Nanomedicine. 2008;3(2):133.

45. Hall JB, Dobrovolskaia MA, Patri AK, Mcneil SE. Characterization of nanoparticles for therapeutics. Nanomedicine. 2007;2(6):789-803.

46. Wang J, Sui M, Fan W. Nanoparticles for tumor targeted therapies and their pharmacokinetics. Curr Drug Metab. 2010;11(2):129-141.

47. Dobrovolskaia MA, Aggarwal P, Hall JB, Mcneil SE. Preclinical studies to understand nanoparticle interaction with the immune system and its potential effects on nanoparticle biodistribution. Mol Pharm. 2008;5(4): 487-495.

48. Dinndorf PA, Gootenberg J, Cohen MH, Keegan P, Pazdur R. FDA drug approval summary: pegaspargase (oncaspar) for the first-line treatment of children with acute lymphoblastic leukemia (ALL). Oncologist. 2007; 12(8):991-998.

49. Tejada-Berges T, Granai CO, Gordinier M, Gajewski W. Caelyx/Doxil for the treatment of metastatic ovarian and breast cancer. Expert Rev Anticancer Ther. 2002;2(2):143-150.

50. Girard PM, Bouchaud O, Goetschel A, et al. Phase II study of liposomal encapsulated daunorubicin in the treatment of AIDS-associated mucocutaneous Kaposi's sarcoma. AIDS. 1996;10(7):753-758.

51. Angst MS, Drover DR. Pharmacology of drugs formulated with DepoFoam $^{\mathrm{TM}}$. Clinical Pharmacokinet. 2006;45(12):1153-1176.

52. Batist G, Barton J, Chaikin P, Swenson C, Welles L. Myocet (liposomeencapsulated doxorubicin citrate): a new approach in breast cancer therapy. Expert Opin Pharmacother. 1739;2002:3.

53. Gradishar WJ. Albumin-bound paclitaxel: a next-generation taxane. Expert Opin Pharmacother. 2006;7(8):1041-1053.

54. Yu L, Ding J. Injectable hydrogels as unique biomedical materials. Chem Soc Rev. 2008;37(8):1473-1481.

55. Fakhari A, Anand Subramony J. Engineered in-situ depot-forming hydrogels for intratumoral drug delivery. J Control Release. 2015; 220(Pt A):465-475.
International Journal of Nanomedicine

\section{Publish your work in this journal}

The International Journal of Nanomedicine is an international, peerreviewed journal focusing on the application of nanotechnology in diagnostics, therapeutics, and drug delivery systems throughout the biomedical field. This journal is indexed on PubMed Central, MedLine, CAS, SciSearch $®$, Current Contents ${ }^{\circledR} /$ Clinical Medicine,
Dovepress

Journal Citation Reports/Science Edition, EMBase, Scopus and the Elsevier Bibliographic databases. The manuscript management system is completely online and includes a very quick and fair peer-review system, which is all easy to use. Visit http://www.dovepress.com/ testimonials.php to read real quotes from published authors. 